\title{
Factors Influencing Acceptance of Personal Health Record Apps for Workplace Health Promotion: Cross-Sectional Questionnaire Study
}

Hyun Sang Park ${ }^{1,2}$, MS; Kwang Il Kim³ ${ }^{3}$ MS; Jae Young Soh ${ }^{1}$, MS; Young Ho Hyun ${ }^{1}$; Sae Kyun Jang ${ }^{4}$, PhD; Sol $\mathrm{Lee}^{4}$; Ga Young Hwang ${ }^{4}$, MS; Hwa Sun Kim ${ }^{5}$, PhD

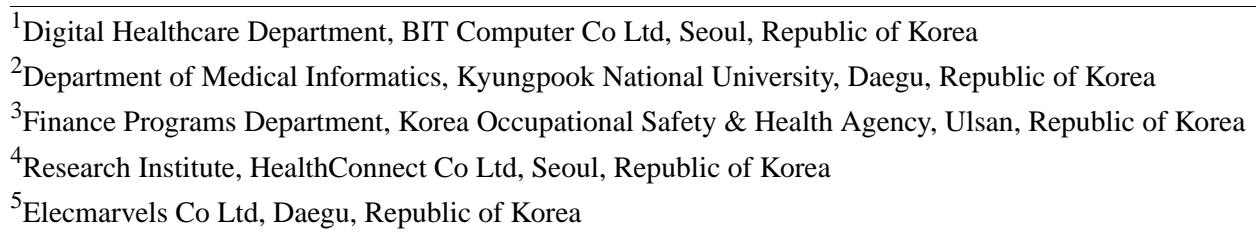

\section{Corresponding Author:}

Hyun Sang Park, MS

Digital Healthcare Department

BIT Computer Co Ltd

BIT Building 33, Seocho-daero 74-gil, Seocho-gu

Seoul

Republic of Korea

Phone: 82234861234 ext 507

Fax: 82234861983

Email: hspark@bit.kr

\section{Abstract}

Background: Health care technologies can help improve workers' health and productivity by supporting workplace health promotion. A personal health record app is used to manage medical data such as results from medical checkups, which facilitates decision making for medical personnel. However, an analysis of users' technology acceptance is required to provide appropriate services based on personal health record apps.

Objective: The purpose of this study was to analyze the factors influencing the behavioral intention of health experts and workers to use an app in workers' health centers and to examine differences in their perception of the main variables.

Methods: The study involved health experts and workers who visited 21 workers' health centers in Korea to verify a research model in which perceived risk was added to the unified theory of acceptance and use of technology, a representative theory of information technology acceptance. After receiving ethical approval from the Korea National Institute for Bioethics Policy, 1050 questionnaires were distributed over 7 weeks with cooperation of the Korea Occupational Safety and Health Agency. A multiple linear regression analysis and multigroup path analysis were performed to verify the hypotheses, and independent samples t tests were performed to analyze differences between workers' and health experts' perception of the main variables.

Results: The analysis included data from 866 respondents (687 workers and 179 health experts). Effort expectancy (beta=.08, $P=.03$ ), social influence (beta=.43, $P<.001$ ), performance expectancy (beta=.07, $P=.008$ ), and facilitating conditions (beta=.13, $P<.001$ ) exerted significant positive effects on behavioral intention, whereas perceived risk (beta=-.29, $P<.001)$ exerted a significant negative effect on behavioral intention. Performance expectancy had a significant effect on path differences depending on gender (critical ratio=-3.38) and age (critical ratio=1.97). Workers' mean scores for the main variables were higher relative to those of health experts for all remaining variables except perceived risk, and significant differences were observed for all remaining variables except facilitating condition.

Conclusions: Social influence exerted the strongest effect on behavioral intention to use the personal health record app. Consequently, it is necessary to coordinate health promotion activities in the workplace as well as the operational direction of community institutions such as in workers' health centers to allow workers to manage their own health via continuous use of the app. In addition, the app should be developed based on a requirement analysis of the balance between both interest groups in consideration of differences in perspective between consumers and service providers. 
(JMIR Mhealth Uhealth 2020;8(6):e16723) doi: 10.2196/16723

\section{KEYWORDS}

personal health record app; workplace health promotion; unified theory of acceptance and use of technology; perceived risk

\section{Introduction}

\section{Background}

Many workers spend most of their waking hours in the workplace [1], which is an environment that can have both positive and negative effects on health [2]. As such, the workplace is the best environment to apply the concept of health promotion. The World Health Organization declared that workplaces should be a priority for health promotion [3]. Workplace health promotion entails employers, workers, and communities working together to improve workers' mental and physical health and overall well-being [4]. Elaborately designed workplace health promotion not only improves workers' health [2] but also positively affects their productivity [5]. The primary challenge in workplace health promotion involves how to increase worker participation, given that less than $50 \%$ of participants typically remain in workplace health promotion programs [6] and the median attrition rate is $28 \%$ [7]. These obstacles can be overcome by incorporating health care technologies (eg, electronic health, mobile health [mHealth], wearable devices) into workplace health promotion strategies [8].

Health care technologies can increase workers' interest, motivation, and participation in workplace health promotion $[9,10]$. These technologies function as cost-effective health promotion and disease prevention mechanisms by allowing workers to monitor their own health. Workers are at increased risk from stress caused by heavy workloads and unhealthy lifestyles, including lack of exercise and frequent drinking, relative to the general public [11]. In particular, office workers sit for long periods of time in the workplace, which exposes them to an increased risk of developing chronic diseases such as heart disease, cerebrovascular disease, and hypertension [12] that are all associated with high mortality rates as the second, third, and ninth most prevalent causes of death in Korea, respectively [13]. The cost associated with the treatment of cardiovascular disease has reached US $\$ 6.9$ billion [14], which is higher than the US $\$ 4.7$ billion spent on cancer, as the most prevalent cause of death, and the burden of disease in Korea is high. Moreover, mortality from cardiovascular disease has steadily increased over the past 10 years [15]. Effective prevention and management are essential because cardiovascular disease not only harms workers' health but also increases medical expenses [16] and contributes to the social burden caused by decreased corporate productivity [17].

Workplace health promotion using health care technology has been shown to improve participants' physical activity and eating habits $[18,19]$. Setting goals, supporting self-monitoring, and providing feedback on changes in physical activity and eating habits can be an effective mechanism for workplace health promotion. Various health care technologies have been studied for efficient workplace health promotion application. Mattila et al [20] conducted a 1-year randomized controlled trial to investigate the activity and usefulness of personal health technologies (web services, mobile apps, and personal monitoring devices) that support workplace health promotion. The authors showed that less than $30 \%$ of subjects continued to use mobile apps and web technologies, and that the key requirements for personal health technologies were simplicity, integration with everyday life, and clear feedback. Cook et al [9] conducted a randomized controlled trial for 3 months to evaluate the effectiveness of a web-based workplace health promotion program and found that web-based programs were more effective than a print-based intervention for improving diet and nutrition, but not for improving stress and physical activity. Balk-Møller et al [21] conducted a randomized controlled trial for 38 weeks to investigate the motivations of workers involved in web and app-based workplace health promotion and reported that social functions were more popular than personal functions, and social factors motivated continued use.

Choia et al [22] studied workers' intention to use health care technology through an investigation of construction workers' acceptance of wearable devices (smart vests and wristbands) for occupational safety and health based on the technology acceptance model (TAM) [23]. They found that perceived usefulness, social influence, and perceived privacy risk were related to the intention to adopt wearable devices. Mohadis et al [24] investigated office workers' acceptance of mHealth apps designed to increase physical activity based on the unified theory of acceptance and use of technology (UTAUT) [25], and found that performance expectancy and social influence had a significant effect on behavioral intention, but not on effort expectation. Sari et al [26] proposed a UTAUT-based conceptual framework to identify factors that influence worker adoption of and intention to use mHealth technology. Technology acceptance of mHealth apps has also been tested in patients with chronic diseases [27], younger adults [28], and health care professionals [29], but related research on workers in workplaces is still in its infancy [30]. Although many mHealth apps have been developed to date, few of these apps have been developed specifically to improve workplace health promotion [31].

Interest in personal health management is rising as aging and the incidence of chronic disease increase [32]. Moreover, active services focused on prevention and health promotion are needed [33] to record lifestyle factors such as exercise, nutrition, and sleep via various wearable devices [34-36] and to measure blood pressure, blood sugar, and weight via personal health devices [37]. Occupational factors such as the workplace environment should also be considered in managing chronic diseases, either by integrating occupational information into the electronic health record (EHR) [38] or implementing the occupational data for health model [39]. Recently, Health Level Seven (HL7) designed a fast health care interoperability resource (FHIR) profile [40] to represent patients' occupational elements in personal health records (PHRs). PHRs are electronic tools that allow secure 
access, management, and sharing of health information [41], which is generally monitored by patients [42]. Individuals can check medical records provided by hospitals, monitor information regarding prescribed medicines and test results, and manage exercise and diet information related to health promotion [43]. Patients can use PHRs to reduce additional medical expenses, and disease management, treatment, and prevention activities can be enhanced as cooperation is improved through communication among medical personnel $[44,45]$.

Employers expect workers to participate in workplace health promotion and enjoy the benefits provided by the organization. In this situation, the concept of PHRs is prominent owing to program technology-based attributes [46]. Employers can provide PHRs that motivate workers' health care [47]. Employer-sponsored PHRs are driven by commercial goals to reduce productivity loss and health insurance costs by promoting a healthy lifestyle [48]. Despite the interest in and expected effects of PHRs, it is difficult to successfully provide these services [49]. Google Health, released in 2008, suspended the service in 2011 because of poor user participation [50], and Microsoft announced in November 2019 that they would stop providing their PHR HealthVault. However, Apple's HealthRecord offers large-scale services that could be linked to over 200 medical institutions as of February 2019. These services are offered free of charge, but users' technology acceptance for PHRs remains low and must be addressed [51]. To implement and operate a successful PHR app service in the workplace, employers, policymakers, developers, and planners must be aware of factors affecting workers' technology acceptance.

Therefore, the purpose of this study was to analyze the factors that influence acceptance of PHR apps in the workplace and examine differences in perceptions surrounding the main factors. We applied a research model that included Bauer's perceived risk [52] as an independent variable to the UTAUT [25], which is widely used to explain acceptance of new information technology.

\section{Theoretical Background and Related Works}

\section{Unified Theory of Technology Acceptance Use}

Previous studies examining the acceptance of new information technology adapted the TAM [23] to research technology. However, the TAM does not adequately support the validity of the relationships between exogenous variables, and is therefore suitable for simple technology acceptance studies but has limited ability to analyze interrelationships in complex environments. Venkatesh et al [25] proposed the UTAUT, which assesses users' technology acceptance from an integrated perspective based on eight representative related theories, including the TAM. The UTAUT model consists of four independent variables (performance expectancy, effort expectancy, social influence, and facilitating conditions) and four moderating variables (gender, age, experience, and voluntariness of use; see Figure 1).

Performance expectancy, effort expectancy, and social influence affect behavioral intention, and facilitating conditions affect use behavior. Performance expectancy is the degree to which system use is perceived to improve work performance; effort expectancy reflects the usability of a system; social influence refers to the degree of awareness that others deemed to be important believe that one should use a new system; and facilitating conditions reflects the degree to which individuals believe that the necessary organization and technical infrastructure are in place to support the use of new systems. These variables are in turn influenced by gender, age, experience, and voluntariness of use when they affect users' behavioral intention and use behavior.

In a previous study, the UTAUT model explained $70 \%$ of behavioral intention and use behavior for an information system, representing a significant improvement in the explanatory power of the model relative to that of existing models, which described $40 \%$ of the technology acceptance [25]. Therefore, the UTAUT model can be used to explain users' technology acceptance of newly developed information technology in medical informatics, which actively converges with other industries. Most previous studies have included electronic medical records [53], PHRs [51], health care devices [54,55], mobile and electronic health services [24,56-59], and telemedicine services [60-63] in the UTAUT model. 
Figure 1. Unified theory of acceptance and use of technology model.

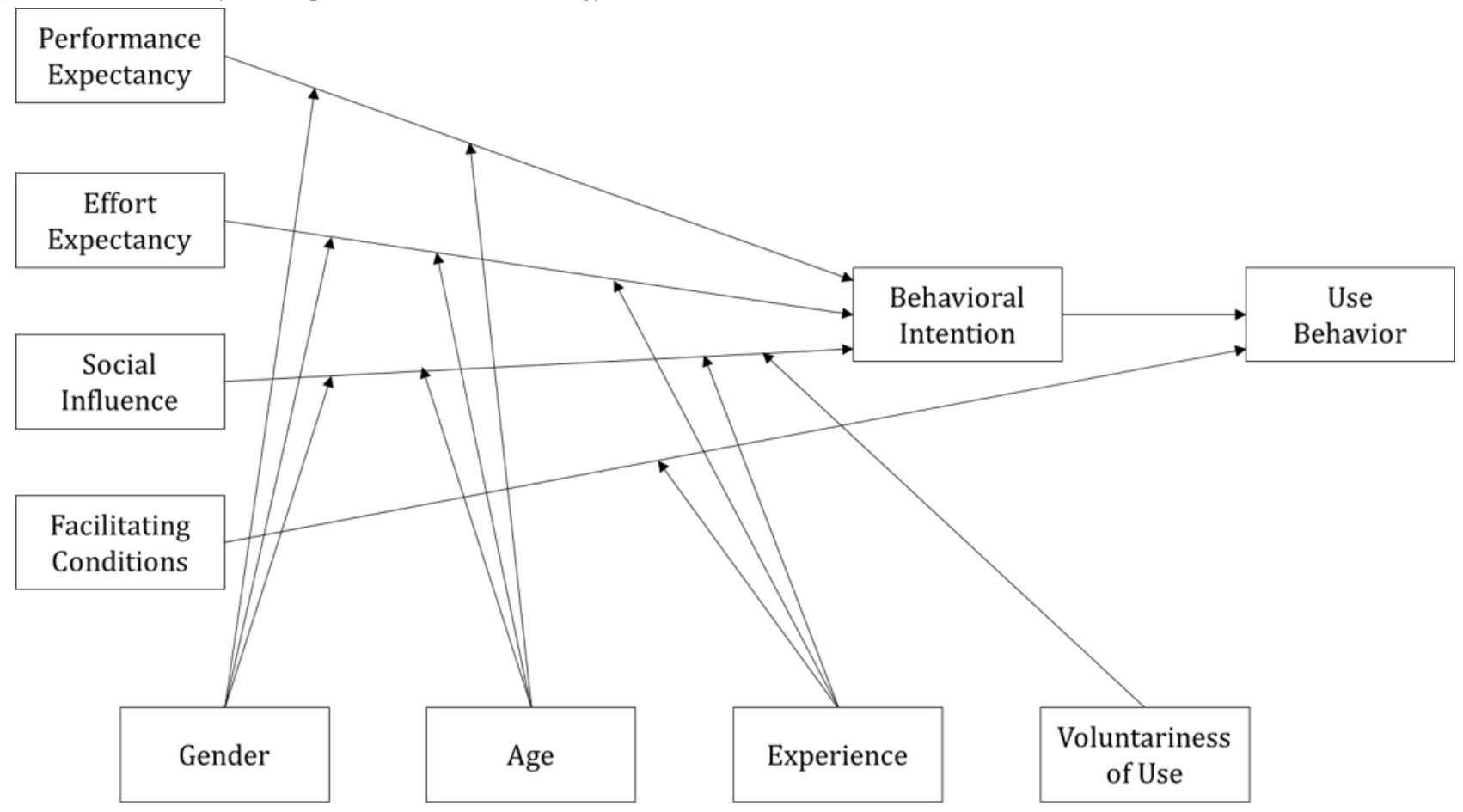

\section{Perceived Risk}

Perceived risk, first introduced by Bauer [52], is the risk subjectively perceived by consumers when performing certain actions such as the uncertainty consumers feel when they cannot predict the outcome of purchase decisions. Short [64] demonstrated that individuals experienced the consequences of this danger; Rayner and Cantor [65] showed the probability of an adverse event occurring and examined subjective assessment of the magnitude of damage incurred by the event. Previous studies $[66,67]$ have examined the effects of perceived risk on users' acceptance. In addition, previous medical informatics studies [68-70] have examined users' perceived risk of mHealth technology and electronic medical records.

\section{Workers' Health Center}

According to a 2017 analysis of industrial accidents [71] conducted by the Ministry of Employment and Labor, of the 993 deaths due to occupational diseases, 354 involved cardiovascular disease, 215 of which occurred at workplaces with fewer than 50 employees. The risk of cardiovascular disease in workers could be decreased via continuous health management according to the results of medical checkups. However, workers in vulnerable classes often do not benefit from systematic industrial health services because they are rarely offered in small-scale workplaces $[72,73]$. The workers' health center was established in Korea in 2011 to meet the rising need for disease prevention and health promotion services in small-scale workplaces.

Workers' health centers are set up in areas with many small-scale workplaces such as industrial parks, and provide services for preventing occupational disease in workers. There are currently 21 workers' health centers in operation in Korea, staffed by professional personnel such as occupational and environmental medicine specialists, occupational nurses, industrial hygiene safety engineers, physical therapists, and counseling psychologists, who provide comprehensive occupational health services, including occupational disease prevention, cerebrovascular disease prevention, musculoskeletal disease prevention, workplace environment counseling, job stress prevention, and lifestyle improvement. Workers' health centers are used by 180,000 workers each year, most of whom are interested in their health care. Workers' health centers manage a vast amount of worker data through the electronic worker health management system.

\section{PHR App}

Our PHR app (Figure 2) manages a worker's PHRs (eg, life $\log$, health information, and medical checkup data) and supports customized health care services and workplace health promotion through links between specific systems and platforms. The worker PHR complies with HL7 FHIR Release 4. The app's primary functions include data collection, text-based health counseling, consultation reservations, sharing PHRs, and viewing occupational health content. For example, workers can collect their own data stored in the workplace or at the workers' health center through the PHR app, manage their PHRs, and receive health counseling services from health experts. In addition, by sharing PHRs to specific platforms through self-certification and consent, analysis results (eg, disease prediction, health, and body age) can be confirmed. PHRs based on data collected at workplaces are the basis for continuous health care, regardless of the worker's external environment (new workplace turnover, local agencies, and hospitals). These data can help decision making for medical personnel by collecting and sharing data among various institutions through our PHR app, which ensures interoperability. 
Figure 2. Personal health record app.

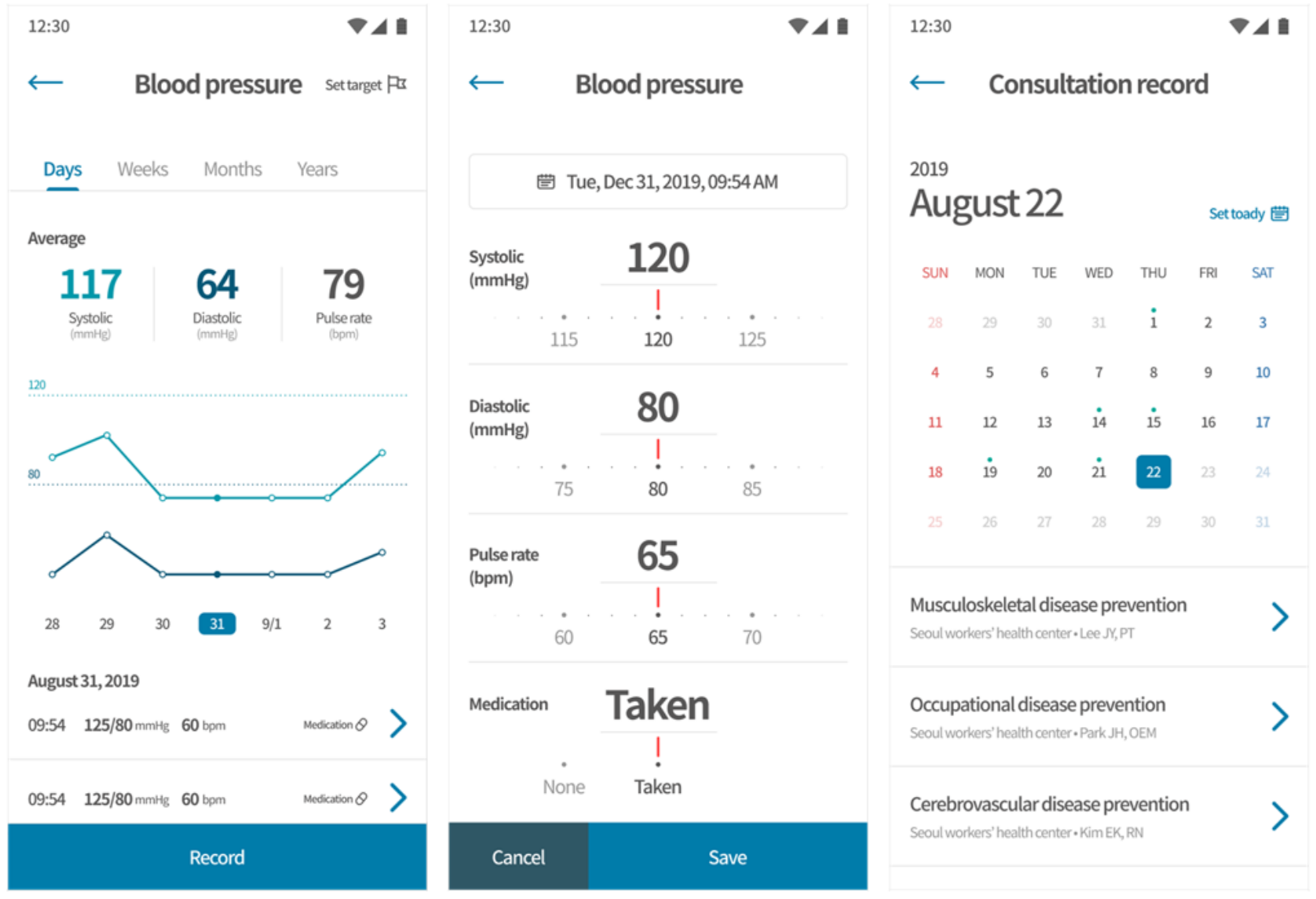

\section{Methods}

\section{Research Model}

The PHR app is an important element of the next generation of health care services and supports personal health promotion by storing and managing important personal medical data in one location. Moreover, using the UTAUT model to analyze and predict users' technology acceptance of the PHR app is a rational approach. In this study, we set the main variables of effort expectancy, social influence, performance expectancy, and facilitating conditions as factors affecting behavioral intention to use the PHR app based on the UTAUT model. In the model, the dependent variable, use behavior, is affected by behavioral intention and facilitating conditions, and behavioral intention is determined by performance expectancy, effort expectancy, and facilitating conditions. However, as PHRs are currently in the introduction stage in Korea, research on actual users is limited. Therefore, in this study, we assumed that facilitating conditions also affected behavioral intention, and therefore included behavioral intention as a dependent variable without considering use behavior. Gender and age were also assumed to moderate the effects of performance expectancy, effort expectancy, and social influence on behavioral intention.

The PHR app is accompanied by various risks, which exert direct effects on behavioral intention. For example, medical data collected and utilized by the PHR app contain highly sensitive information, and behavioral intention decreases when there is a high probability of a data breach or fraud. In addition, behavioral intention decreases when users cannot securely manage as much information as they expected, or believe their information will be used for other purposes. These risks should be minimized when introducing health care services based on the PHR. Therefore, this study extended the existing UTAUT model by including perceived risk as a main variable (Figure $3)$. 
Figure 3. Research model.

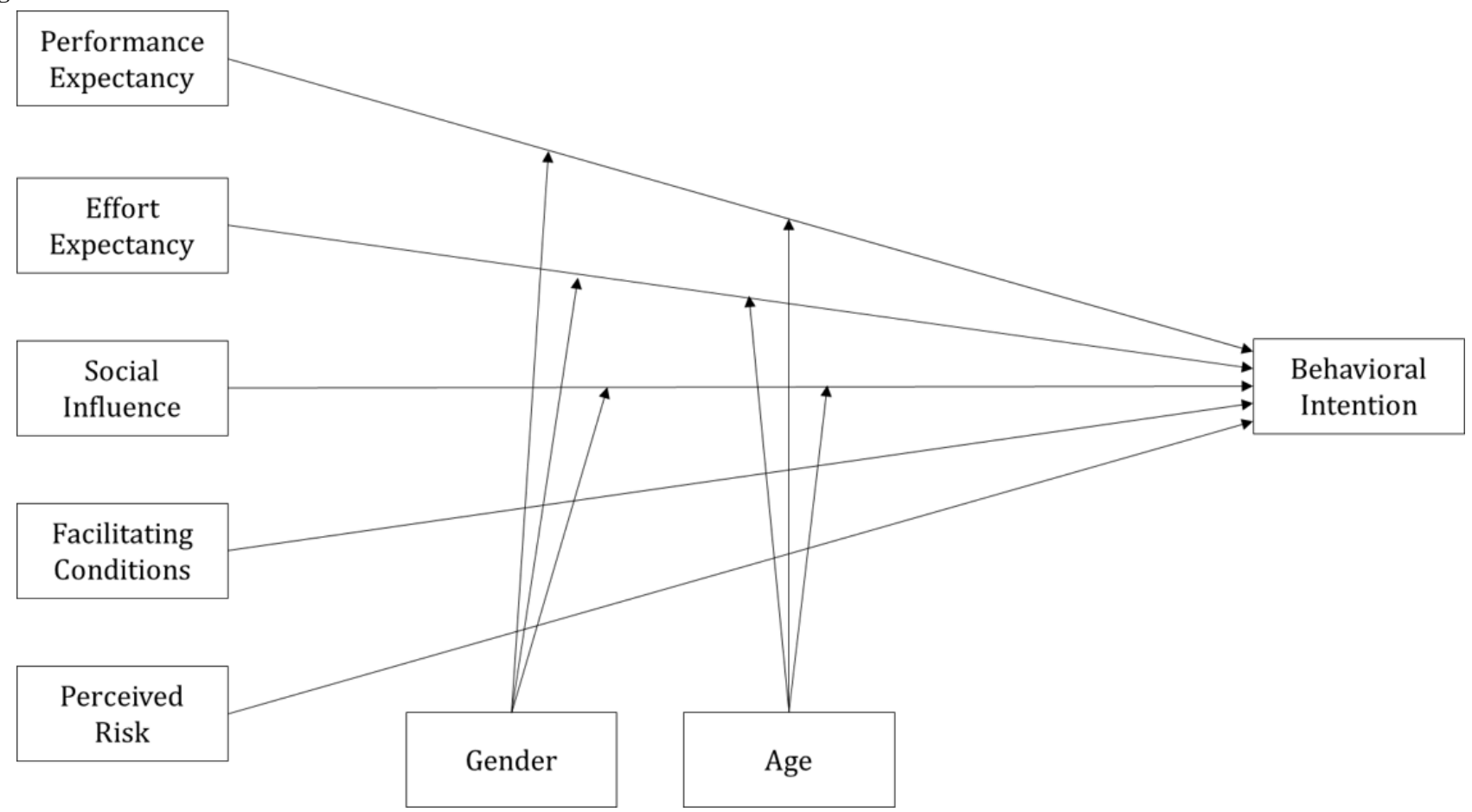

\section{Research Hypotheses}

Performance expectancy is defined as "the degree to which an individual believes that using the system will help improve his or her performance" [25]. Performance expectancy is similar to the perceived usefulness of the TAM [23]. In this study, performance expectancy refers to the degree to which users believe that using the PHR app will help them improve their health. The PHR app not only collects and manages the worker's own data but also improves motivation and participation for workplace health promotion through personalized feedback from health experts [74-77]. Previous studies have demonstrated that performance expectancy and usefulness affect behavioral intention [51,63,78-80]. Therefore, we proposed the following hypothesis, H1: Performance expectancy in the PHR app will exert a positive effect on behavioral intention.

Effort expectancy is defined as "the degree of ease associated with the use of the system" [25], and affects the intent to use and the ease with which users can learn and use the system, similar to the TAM's perceived ease of use [23] and innovation diffusion theory [81]. In this study, effort expectancy refers to the PHR app's ease of use; the app should be easy to use, taking workers' diversity into account (eg, age, type of business). Given that hard-to-use functions have a negative impact on users [82], PHR app functions should make it easy for users to access their data. Previous studies have shown that ease of use affects behavioral intention $[51,83,84]$. Therefore, we proposed the following hypothesis, H2: Effort expectancy in the PHR app will exert a positive effect on behavioral intention.

Social influence is defined as "the degree to which an individual perceives that important others believe that he or she should use the new system" [25]. In this study, social influence refers to the degree to which users feel that others deemed to be important or work colleagues believe that the user should use the PHR app for enhanced health management. Social influence is associated with organizational culture in the workplace [85], which is known to be an important social characteristic that affects organization, group, and individual behavior [86-89]. Social influence is an important factor in workers' communications and interactions with their colleagues [90], which has been identified as a suitable factor for technology acceptance in previous studies [55,91-93]. Therefore, we proposed the following hypothesis, H3: Social influence in the PHR app will exert a positive effect on behavioral intention.

Facilitating conditions are defined as "the degree to which an individual believes that an organizational and technical infrastructure exists to support the use of a given system" [25]. In this study, facilitating conditions refers to a user's belief that an organizational and technical infrastructure exists to support PHR app use. The number of aging individuals is rapidly increasing. Older workers are less capable of acquiring and adopting new technologies such as information and communication technology, and need adequate training and technical support for using such tools. Previous studies have shown that facilitating conditions affect workers' behavioral intention to use new technology [94-96]. Therefore, we proposed the following hypothesis, H4: Facilitating conditions in the PHR app will exert a positive effect on behavioral intention.

Perceived risk is defined as "the uncertainty due to unforeseen consequences" [52]. In this study, perceived risk refers to the degree to which users are aware of possible loss associated with uncertainty surrounding PHR app use. Since workplaces require insight into the health status of their organizations and workers, personal health data should be strictly protected [97]. The health manager in the workplace handles sensitive medical data such as workers' medical checkups and data from individuals who have abnormal findings; the PHR app collects and manages these data. Confidence in the system, information privacy, and 
security concerns affect the sharing behavior of PHRs [98]. Therefore, we propose the following hypothesis, H5: Perceived risk in the PHR app will exert a negative effect on behavioral intention.

In UTAUT, performance expectancy, effort expectancy, and social influence are moderated by gender, age, experience, and the voluntary nature of use [25]. Gender and age are generally perceived as significant factors in attitudes toward information technology [99], which previous studies have treated as moderating variables in technology acceptance [100-102]. Therefore, we proposed the following hypotheses: H6, Effects of performance expectancy on behavioral intention of the PHR app will be moderated by gender and age; H7, Effects of effort expectancy on behavioral intention of the PHR app will be moderated by gender and age; and

H8, Effects of social influence on behavioral intention of the PHR app will be moderated by gender and age.

\section{Instrument Development}

The questionnaire consisted of 42 items. Responses to the 21 items (see Multimedia Appendix 1) measuring the main variables were on a 5-point Likert scale ranging from "strongly disagree" to "strongly agree" (Table 1). In addition, 12 items pertained to participants' general characteristics and 9 items concerned the experience of and functions required of the app.

Table 1. Definition of variables.

\begin{tabular}{|c|c|c|c|}
\hline Variable & Definition & Number of questions & Reference \\
\hline Behavioral Intention & The degree of users' behavioral intention to use the $\mathrm{PHR}^{\mathrm{a}}$ app & 3 & {$[25]$} \\
\hline Performance Expectancy & $\begin{array}{l}\text { The degree to which users believe that using the PHR app will help them to im- } \\
\text { prove their health }\end{array}$ & 3 & {$[24,25]$} \\
\hline Effort Expectancy & Ease of use for the PHR app & 4 & {$[24,25]$} \\
\hline Social Influence & $\begin{array}{l}\text { The degree to which users feel that important others or work colleagues believe } \\
\text { that the PHR app should be used for enhanced health management }\end{array}$ & 4 & {$[22,24,25]$} \\
\hline Facilitating Conditions & $\begin{array}{l}\text { The degree to which users believe that an organizational and technical infrastruc- } \\
\text { ture exists to support use of the PHR app }\end{array}$ & 4 & {$[2,25]$} \\
\hline Perceived Risk & $\begin{array}{l}\text { The degree to which users are aware of possible loss relating to uncertainty sur- } \\
\text { rounding use of the PHR app }\end{array}$ & 3 & {$[52]$} \\
\hline
\end{tabular}

${ }^{\text {a} P H R: ~ p e r s o n a l ~ h e a l t h ~ r e c o r d . ~}$

\section{Data Collection and Analysis}

After receiving ethical approval (IRB No. P01-201902-23-014) from the Korea National Institute for Bioethics Policy, we recruited workers and health experts who visited 21 worker health centers with cooperation of the Korea Occupational Safety and Health Agency. The survey included 40 workers and 10 health experts from each worker health center and considered regional distribution.

We used a paper-based questionnaire to verify the proposed research model. The survey was conducted for approximately 7 weeks from February 12 to April 6, 2019. In total, 1050 questionnaires were distributed and 900 were collected. Of the collected questionnaires, we removed 34 that were inappropriate for analysis because they did not meet the purpose of the study or included insincere responses.

Frequency statistics were used to analyze the participants' general characteristics. Reliability analysis, exploratory factor analysis, and confirmatory factor analysis were used to assess the instrument's reliability and validity. Correlation analysis was used to examine bivariate associations among the main variables. Multiple linear regression analysis was employed to verify the explanatory power and hypotheses of the research model. Multigroup path analysis was performed to verify the effect of moderating variables, and critical ratios for differences were calculated to verify the statistical significance of the path coefficient for each group. Independent samples $t$ tests were applied to analyze differences in perception of the main variables. For frequency analysis and independent samples $t$ tests, the participants were divided into workers and health experts, and the remaining analyses were based on all respondents.

We used the factor extraction method, which implements the most commonly used maximum-likelihood estimation, in common factor analysis; for factor rotation, we used the direct Oblimin method in the square rotation to examine correlations between the factors. The determination criterion for the number of factors extracted was an eigenvalue $>1$. The Kaiser Meyer Olkin index was used to test the suitability of factors for analysis, where values of 0.5-1.0 indicate that the factors are suitable for analysis and those $\leq 0.5$ indicate that the factors are not suitable for analysis. Pearson correlation analysis was performed to examine bivariate correlations before performing multiple linear regression analysis. Correlation analysis was performed using factor score storage values in the factor analysis. In the social sciences, coefficients below \pm 0.2 are considered low, those between \pm 0.3 and \pm 0.7 are considered moderate, and those above \pm 0.7 are considered high [103]. Analyses were performed with IBM SPSS Statistics ver. 25.0 and AMOS 22 (IBM Corp, Armonk, NY, USA). 


\section{Results}

\section{Participant Characteristics}

The study involved 866 participants, including 179 health experts and 687 workers who visited 21 workers' health centers nationwide. Workers' general characteristics are summarized in Table 2. The majority of the workers were women. Most participants were older than 50 years, followed by those in their $40 \mathrm{~s}$ and 30s. The duration of employment in the workplace was most commonly $1-4$ years, and $66.1 \%$ (454/687) of workers were employed in workplaces with $<50$ employees. Clerical and service-based businesses were more common than production and technical businesses.

Health experts' characteristics are shown in Table 3. Similar to the workers, the majority of respondents were women. The most common age group was 30-39 years and the duration of employment in the workplace was most commonly 1-4 years. The most common type of occupation was nursing, followed by physical therapy, industrial hygiene safety engineering, counseling psychology, occupational and environmental medicine, and other. 
Table 2. Characteristics of the workers $(\mathrm{N}=687)$.

\begin{tabular}{|c|c|}
\hline Characteristic & $\mathrm{n}(\%)$ \\
\hline \multicolumn{2}{|l|}{ Gender } \\
\hline Male & $266(38.7)$ \\
\hline Female & $421(61.3)$ \\
\hline \multicolumn{2}{|l|}{ Age (years) } \\
\hline$<20$ & $2(0.3)$ \\
\hline $20-29$ & $124(18.0)$ \\
\hline 30-39 & $159(23.1)$ \\
\hline $40-49$ & $165(24.0)$ \\
\hline$\geq 50$ & $237(34.5)$ \\
\hline \multicolumn{2}{|l|}{ Marital status } \\
\hline Single & $207(30.1)$ \\
\hline Married & $462(67.2)$ \\
\hline Widowed & $10(1.5)$ \\
\hline Divorced or separated & $8(1.2)$ \\
\hline \multicolumn{2}{|l|}{ Education } \\
\hline Middle school & $34(4.9)$ \\
\hline High school & $190(27.7)$ \\
\hline College ( 2 years) & $100(14.6)$ \\
\hline College (4 years) & $313(45.6)$ \\
\hline Graduate school & $50(7.3)$ \\
\hline \multicolumn{2}{|c|}{ Time in the workplace (years) } \\
\hline$<1$ & $111(16.2)$ \\
\hline $1-4$ & $251(36.5)$ \\
\hline $5-9$ & $138(20.1)$ \\
\hline$\geq 10$ & $187(27.2)$ \\
\hline \multicolumn{2}{|c|}{ Number of employees in the workplace } \\
\hline$<5$ & $82(11.9)$ \\
\hline $5-9$ & $105(15.3)$ \\
\hline $10-29$ & $173(25.2)$ \\
\hline $30-49$ & 94 (13.7) \\
\hline $50-99$ & $53(7.7)$ \\
\hline$\geq 100$ & $180(26.2)$ \\
\hline \multicolumn{2}{|l|}{ Type of business } \\
\hline Production & $67(9.8)$ \\
\hline Clerical & $271(39.4)$ \\
\hline Service-based & $226(32.9)$ \\
\hline Technical & $54(7.9)$ \\
\hline Other & $69(10.0)$ \\
\hline
\end{tabular}


Table 3. Characteristics of health experts $(\mathrm{N}=179)$.

\begin{tabular}{|c|c|}
\hline Characteristic & $\mathrm{n}(\%)$ \\
\hline \multicolumn{2}{|l|}{ Gender } \\
\hline Male & $45(25.1)$ \\
\hline Female & $134(74.9)$ \\
\hline \multicolumn{2}{|l|}{ Age (years) } \\
\hline $20-29$ & $27(15.1)$ \\
\hline $30-39$ & $104(58.1)$ \\
\hline $40-49$ & $35(19.6)$ \\
\hline$\geq 50$ & $13(7.3)$ \\
\hline \multicolumn{2}{|l|}{ Marital status } \\
\hline Single & $75(41.9)$ \\
\hline Married & $103(57.5)$ \\
\hline Divorced or separated & $1(0.6)$ \\
\hline \multicolumn{2}{|l|}{ Education } \\
\hline College ( 2 years) & $28(15.6)$ \\
\hline College (4 years) & $95(53.1)$ \\
\hline Graduate school & $56(31.3)$ \\
\hline \multicolumn{2}{|l|}{ Time in the workplace (years) } \\
\hline$<1$ & $30(16.8)$ \\
\hline $1-4$ & $79(44.1)$ \\
\hline $5-9$ & $43(24.0)$ \\
\hline$\geq 10$ & $27(15.1)$ \\
\hline \multicolumn{2}{|l|}{ Type of occupation } \\
\hline Occupational and environmental medicine & $11(6.2)$ \\
\hline Nursing & $75(41.9)$ \\
\hline Physical therapy & $49(27.4)$ \\
\hline Counseling psychologist & $16(8.9)$ \\
\hline Industrial hygiene safety engineering & $23(12.8)$ \\
\hline Other & $5(2.8)$ \\
\hline
\end{tabular}

\section{Reliability and Validity Analysis}

The results of the reliability and exploratory factor analyses are shown in Table 4. Cronbach alpha values greater than .60 and .90 are generally considered acceptable and highly reliable, respectively. Cronbach alpha values for all variables, excluding perceived risk (.69), were within the recommended range $(>0.70)$, and thus the reliability of the main variables was considered acceptable. The analysis was performed without deleting items because none of the items impaired reliability.

The Kaiser Meyer Olkin statistic was 0.90 and the result of the Barlett test was Chi square $_{210}=14334.09(P<.001)$; thus, the factor analysis model was considered suitable. In addition, the cumulative variance was $70.63 \%$ and the explanatory power of the six factors was high. All factor loading values were above 0.4 , which demonstrated the validity of the overall instrument; therefore, the analysis was performed without additional adjustment.
The fit indices for the research model were as follows: Chi square $_{174}=819.66(P<.001)$, goodness-of-fit index $=0.91$, root mean square residual $=0.04$, root mean square error of approximation $=0.07$, normed fit index $=0.94$, relative fit index $=0.93$, incremental fit index $=0.96$, comparative fit index $=0.95$, Tucker-Lewis index $=0.95$, and adjusted goodness-of-fit-index $=0.88$. The adjusted goodness-of-fit-index did not meet the criteria, but the overall model fit was satisfactory, and the other indices met the criteria. The results of confirmatory factor analysis (Table 5) showed that the paths to the observed variables were significant $(P<.001)$ for all latent variables. The average variance extracted was $>0.50$ and the construct reliability was $>0.70$; therefore, convergent validity was demonstrated. In addition, the discriminant validity ensured that the average variance extracted was higher than the square value of the correlation coefficient (Table 6). 
Table 4. Reliability and exploratory factor analysis.

\begin{tabular}{|c|c|c|c|c|c|c|c|}
\hline Variable & Factor 1 & Factor 2 & Factor 3 & Factor 4 & Factor 5 & Factor 6 & Cronbach alpha \\
\hline BI ${ }^{\mathrm{a}}$ (loading) & & & & & & & .95 \\
\hline BI1 & 0.93 & 0.02 & 0.01 & -0.02 & 0.04 & -0.01 & \\
\hline BI2 & 0.88 & 0.05 & 0.04 & 0.01 & 0.03 & -0.02 & \\
\hline $\mathrm{BI} 3$ & 0.80 & 0.01 & 0.06 & 0.05 & 0.06 & -0.03 & \\
\hline $\mathbf{E E}^{\mathbf{b}}$ (loading) & & & & & & & .96 \\
\hline EE1 & 0.01 & 0.96 & -0.02 & -0.01 & -0.03 & 0.01 & \\
\hline EE2 & -0.004 & 0.94 & 0.01 & -0.01 & 0.01 & -0.01 & \\
\hline EE3 & -0.02 & 0.89 & 0.02 & -0.02 & 0.09 & -0.01 & \\
\hline EE4 & 0.04 & 0.83 & 0.01 & 0.06 & -0.02 & -0.02 & \\
\hline $\mathrm{SI}^{\mathbf{c}}$ (loading) & & & & & & & .92 \\
\hline SI1 & -0.03 & 0.04 & 0.92 & -0.01 & -0.02 & 0.03 & \\
\hline SI2 & 0.01 & -0.03 & 0.89 & -0.02 & 0.02 & -0.03 & \\
\hline SI3 & 0.08 & -0.04 & 0.81 & -0.01 & 0.06 & -0.07 & \\
\hline SI4 & 0.02 & 0.06 & 0.76 & 0.05 & -0.03 & 0.04 & \\
\hline $\mathrm{PE}^{\mathrm{d}}$ (loading) & & & & & & & .79 \\
\hline PE1 & 0.09 & 0.01 & -0.07 & 0.80 & -0.01 & -0.03 & \\
\hline PE2 & -0.14 & -0.02 & 0.05 & 0.74 & 0.05 & 0.02 & \\
\hline PE3 & 0.16 & 0.05 & 0.02 & 0.67 & -0.03 & -0.02 & \\
\hline FC $^{\mathrm{e}}$ (loading) & & & & & & & .87 \\
\hline $\mathrm{FC} 1$ & -0.07 & 0.07 & -0.05 & .001 & 0.88 & 0.02 & \\
\hline $\mathrm{FC} 2$ & 0.08 & -0.04 & -0.07 & 0.01 & 0.82 & 0.02 & \\
\hline $\mathrm{FC} 3$ & 0.08 & 0.05 & 0.07 & 0.01 & 0.68 & -0.04 & \\
\hline $\mathrm{FC} 4$ & 0.01 & 0.03 & 0.17 & 0.03 & 0.62 & -0.05 & \\
\hline PR $\mathbf{f}^{\mathbf{f}}$ (loading) & & & & & & & .69 \\
\hline PR1 & 0.09 & -0.003 & 0.06 & 0.003 & -0.09 & 0.84 & \\
\hline PR2 & -0.05 & -0.06 & -0.02 & 0.04 & -0.03 & 0.65 & \\
\hline PR3 & -0.05 & 0.02 & -0.05 & -0.05 & 0.08 & 0.48 & \\
\hline Eigenvalue & 8.03 & 1.97 & 1.41 & 1.37 & 1.11 & 0.94 & \\
\hline Variance (\%) & 38.25 & 9.37 & 6.74 & 6.50 & 5.29 & 4.49 & \\
\hline Cumulative variance $(\%)$ & 38.25 & 47.61 & 54.35 & 60.85 & 66.15 & 70.63 & .87 \\
\hline
\end{tabular}

${ }^{\mathrm{a} B I}$ : behavioral intention.

${ }^{b}$ EE: effort expectancy.

${ }^{\mathrm{c}} \mathrm{SI}$ : social influence.

${ }^{\mathrm{d}} \mathrm{PE}$ : performance expectancy.

${ }^{\mathrm{e}} \mathrm{FC}$ : facilitating conditions.

${ }^{\mathrm{f}} \mathrm{PR}$ : perceived risk. 
Table 5. Confirmatory factor analysis.

\begin{tabular}{|c|c|c|c|c|c|c|c|}
\hline Latent and observed variables & $\mathrm{B}$ & beta & SE & Critical ratio & $P$ value & $\mathrm{AVE}^{\mathrm{a}}$ & $\mathrm{CR}^{\mathrm{b}}$ \\
\hline \multicolumn{6}{|l|}{$\mathbf{B I}^{\mathrm{c}}$} & 0.90 & 0.96 \\
\hline BI1 & 1.07 & .96 & 0.02 & 47.39 & $<.001$ & & \\
\hline BI2 & 1.06 & .96 & 0.02 & 47.77 & $<.001$ & & \\
\hline BI3 & 1.00 & .89 & $\mathrm{~N} / \mathrm{A}^{\mathrm{d}}$ & N/A & N/A & & \\
\hline \multicolumn{6}{|l|}{$\mathbf{E} \mathbf{E}^{\mathbf{e}}$} & 0.87 & 0.96 \\
\hline EE1 & 0.90 & .86 & 0.02 & 41.82 & $<.001$ & & \\
\hline EE2 & 1.04 & .92 & 0.02 & 54.17 & $<.001$ & & \\
\hline EE3 & 1.00 & .96 & N/A & N/A & N/A & & \\
\hline EE4 & 0.99 & .93 & 0.02 & 56.61 & $<.001$ & & \\
\hline \multicolumn{6}{|l|}{$\mathrm{SI}^{\mathbf{f}}$} & 0.75 & 0.92 \\
\hline SI1 & 1.01 & .90 & 0.03 & 38.50 & $<.001$ & & \\
\hline SI2 & 0.98 & .88 & 0.03 & 36.89 & $<.001$ & & \\
\hline SI3 & 1.00 & .89 & N/A & N/A & N/A & & \\
\hline SI4 & 0.92 & .78 & 0.03 & 29.17 & $<.001$ & & \\
\hline \multicolumn{6}{|l|}{$\mathbf{P E}^{\mathrm{g}}$} & 0.72 & 0.88 \\
\hline PE1 & 0.89 & .77 & 0.05 & 19.19 & $<.001$ & & \\
\hline PE2 & 0.87 & .67 & 0.05 & 17.68 & $<.001$ & & \\
\hline PE3 & 1 & .82 & N/A & N/A & N/A & & \\
\hline \multicolumn{6}{|l|}{$F C^{h}$} & 0.65 & 0.88 \\
\hline $\mathrm{FC} 1$ & 0.99 & .77 & 0.04 & 24.14 & $<.001$ & & \\
\hline $\mathrm{FC} 2$ & 1.12 & .85 & 0.04 & 26.80 & $<.001$ & & \\
\hline FC3 & 1 & .80 & N/A & N/A & N/A & & \\
\hline $\mathrm{FC} 4$ & 0.90 & .74 & 0.04 & 22.76 & $<.001$ & & \\
\hline \multicolumn{6}{|l|}{$\mathbf{P R}^{\mathbf{i}}$} & 0.50 & 0.75 \\
\hline PR1 & 1.25 & .76 & 0.10 & 12.30 & $<.001$ & & \\
\hline PR2 & 1.27 & .74 & 0.10 & 12.29 & $<.001$ & & \\
\hline PR3 & 1 & .50 & N/A & N/A & N/A & & \\
\hline
\end{tabular}

${ }^{\mathrm{a} A V E}$ : average variance extracted.

${ }^{\mathrm{b}} \mathrm{CR}$ : composite reliability.

${ }^{\mathrm{c}} \mathrm{BI}$ : behavioral intention.

${ }^{\mathrm{d}} \mathrm{N} / \mathrm{A}$ : not applicable.

${ }^{\mathrm{e}}$ EE: effort expectancy.

${ }^{\mathrm{f}}$ SI: social influence.

${ }^{\mathrm{g}} \mathrm{PE}$ : performance expectancy.

${ }^{\mathrm{h}} \mathrm{FC}$ : facilitating conditions.

${ }^{\mathrm{i}} \mathrm{PR}$ : perceived risk. 
Table 6. Discriminant validity analysis.

\begin{tabular}{|c|c|c|c|c|c|c|}
\hline & $\mathrm{BI}^{\mathrm{a}}$ & $\mathrm{EE}^{\mathrm{b}}$ & $\mathrm{SI}^{\mathrm{c}}$ & $\mathrm{PE}^{\mathrm{d}}$ & $\mathrm{FC}^{\mathrm{e}}$ & $P R^{f}$ \\
\hline BI & 1 & & & & & \\
\hline $\mathrm{EE}$ & $.29^{\mathrm{g}}$ & 1 & & & & \\
\hline SI & $.39^{\mathrm{g}}$ & $.21^{\mathrm{g}}$ & 1 & & & \\
\hline $\mathrm{PE}$ & $.15^{\mathrm{g}}$ & $.10^{\mathrm{g}}$ & $.08^{\mathrm{g}}$ & 1 & & \\
\hline FC & $.23^{\mathrm{g}}$ & $.45^{\mathrm{g}}$ & $.10^{\mathrm{g}}$ & $.06^{\mathrm{g}}$ & 1 & \\
\hline PR & $.25^{\mathrm{g}}$ & $.18^{\mathrm{g}}$ & $.09^{\mathrm{g}}$ & $.09^{\mathrm{g}}$ & $.14^{\mathrm{g}}$ & 1 \\
\hline $\mathrm{AVE}^{\mathrm{h}}$ & .90 & .87 & .75 & .72 & .65 & .50 \\
\hline $\mathrm{CR}^{\mathrm{i}}$ & .96 & .96 & .92 & .88 & .88 & .75 \\
\hline
\end{tabular}

${ }^{\mathrm{a}} \mathrm{BI}$ : behavioral intention.

${ }^{b}$ EE: effort expectancy.

${ }^{\mathrm{c}} \mathrm{SI}$ : social influence.

${ }^{\mathrm{d}} \mathrm{PE}$ : performance expectancy.

${ }^{\mathrm{e}} \mathrm{FC}$ : facilitating conditions.

${ }^{\mathrm{f}} \mathrm{PR}$ : perceived risk.

${ }^{\mathrm{g}} P<.01$.

${ }^{\mathrm{h}} \mathrm{AVE}$ : average variance extracted.

${ }^{\mathrm{i}} \mathrm{CR}$ : composite reliability.

\section{Hypothesis Testing}

The results of Pearson correlation analysis showed that all dependent variables and the independent variable in the research model were significantly correlated (Table 7). In particular, perceived risk was negatively correlated with all other variables.

We performed multiple linear regression analysis to verify the effects of effort expectancy, social influence, performance expectancy, facilitating conditions, and perceived risk on behavioral intention. The factor analysis results showed that the regression model was statistically significant $(F=194.96$, $P<.001)$, as shown in Table 8 . The explanatory power of the regression model was $53.1 \%\left(R^{2}=0.53, a d j R^{2}=0.53\right)$. Moreover, no issues were observed with respect to the independence of residuals $(\mathrm{D}-\mathrm{W}=2.04)$ or multicollinearity (variance inflation factor $<10)$.

The regression coefficients showed that effort expectancy, social influence, performance expectancy, and facilitating conditions exerted significant positive effects on behavioral intention, whereas perceived risk exerted a significant negative effect on behavioral intention (Table 8). Therefore, the results supported $\mathrm{H} 1, \mathrm{H} 2, \mathrm{H} 3, \mathrm{H} 4$, and $\mathrm{H} 5$.

We performed multigroup path analysis to verify the moderating effects of gender and age (Table 9). In the male group, effort expectancy, social influence, and performance expectancy exerted significant positive effects on behavioral intention. In the female group, effort expectancy, social influence, and performance expectancy exerted significant positive effects on behavioral intention. Only the performance expectancy (critical ratio=-3.38, $P<.001$ ) showed statistically significant differences in the path between males and females.

In the younger group, effort expectancy, social influence, and performance expectancy exerted significant positive effects on behavioral intention. In the older group, effort expectancy, social influence, and performance expectancy exerted significant positive effects on behavioral intention. Only the performance expectancy (critical ratio=1.97) showed statistically significant differences in the path between younger and older respondents. Therefore, the results supported H6, but $\mathrm{H} 7$ and $\mathrm{H} 8$ were rejected.

The path analysis of workers and health experts showed that effort expectancy, social influence, performance expectancy, and facilitating conditions exerted significant positive effects on behavioral intention, whereas perceived risk exerted a significant negative effect on behavioral intention. Only the perceived risk (critical ratio=-2.24) showed statistically significant differences in the path between workers and health experts. 
Table 7. Pearson correlation coefficients among dependent variables.

\begin{tabular}{|c|c|c|c|c|c|c|}
\hline & $\mathrm{BI}^{\mathrm{a}}$ & $E E^{b}$ & $\mathrm{SI}^{\mathrm{c}}$ & $P E^{d}$ & $\mathrm{FC}^{\mathrm{e}}$ & $P R^{f}$ \\
\hline BI & 1.00 & & & & & \\
\hline $\mathrm{EE}$ & $0.51^{\mathrm{g}}$ & 1.00 & & & & \\
\hline SI & $0.61^{\mathrm{g}}$ & $0.47^{\mathrm{g}}$ & 1.00 & & & \\
\hline PE & $0.33^{\mathrm{g}}$ & $0.20^{\mathrm{g}}$ & $0.28^{\mathrm{g}}$ & 1.00 & & \\
\hline FC & $0.42^{\mathrm{g}}$ & $0.67^{\mathrm{g}}$ & $0.28^{\mathrm{g}}$ & $0.21^{\mathrm{g}}$ & 1.00 & \\
\hline PR & $-0.53^{\mathrm{g}}$ & $-0.42^{\mathrm{g}}$ & $-0.32^{\mathrm{g}}$ & $-0.31^{\mathrm{g}}$ & $-0.34^{\mathrm{g}}$ & 1.00 \\
\hline
\end{tabular}

${ }^{\mathrm{a}} \mathrm{BI}$ : behavioral intention.

${ }^{b}$ EE: effort expectancy.

${ }^{\mathrm{c}}$ SI: social influence.

${ }^{\mathrm{d}} \mathrm{PE}$ : performance expectancy.

${ }^{\mathrm{e}} \mathrm{FC}$ : facilitating conditions.

${ }^{\mathrm{f}} \mathrm{PR}$ : perceived risk.

$\mathrm{g}_{P}<.01$

Table 8. Multiple linear regression analysis with behavioral intention as the dependent variable.

\begin{tabular}{|c|c|c|c|c|c|c|}
\hline Independent variables & $\mathrm{B}$ & SE & beta & $t_{865}$ & $P$ value & $\mathrm{VIF}^{\mathrm{a}}$ \\
\hline (Constant) & $-6.95 \mathrm{E}-17$ & 0.02 & & 0.00 & $>.99$ & \\
\hline $\mathrm{EE}^{\mathrm{b}}$ & 0.08 & 0.04 & .08 & 2.17 & .03 & 2.24 \\
\hline $\mathrm{SI}^{\mathrm{c}}$ & 0.43 & 0.03 & .43 & 15.73 & $<.001$ & 1.34 \\
\hline$P E^{d}$ & 0.07 & 0.03 & .07 & 2.67 & .008 & 1.17 \\
\hline $\mathrm{FC}^{\mathrm{e}}$ & 0.14 & 0.03 & .13 & 4.30 & $<.001$ & 1.81 \\
\hline$P R^{f}$ & -0.32 & 0.03 & -.29 & -10.99 & $<.001$ & 1.31 \\
\hline
\end{tabular}

${ }^{\mathrm{a}}$ VIF: variable inflation factor.

${ }^{b}$ EE: effort expectancy.

${ }^{\mathrm{c}} \mathrm{SI}$ : social influence.

${ }^{\mathrm{d}} \mathrm{PE}$ : performance expectancy.

${ }^{\mathrm{e}} \mathrm{FC}$ : facilitating conditions.

${ }^{\mathrm{f}} \mathrm{PR}$ : perceived risk. 
Table 9. Multigroup path analysis.

\begin{tabular}{|c|c|c|c|c|c|c|c|c|c|}
\hline \multirow[t]{2}{*}{ Path } & \multicolumn{4}{|c|}{ Male/ Younger ( $<39$ years)/Workers } & \multicolumn{4}{|c|}{ Female/Older ( $\geq 40$ years)/Health experts } & \multirow{2}{*}{$\begin{array}{l}\text { Critical ratio for } \\
\text { difference }\end{array}$} \\
\hline & $\mathrm{B}$ & beta & SE & $P$ value & B & beta & SE & $P$ value & \\
\hline \multicolumn{10}{|c|}{ Gender (Male or Female) } \\
\hline $\mathrm{EE}^{\mathrm{a}}$ to $\mathrm{BI}^{\mathrm{b}}$ & 0.10 & .09 & 0.07 & .02 & 0.08 & .11 & 0.05 & .02 & -0.91 \\
\hline $\mathrm{SI}^{\mathrm{c}}$ to $\mathrm{BI}$ & 0.38 & .40 & 0.05 & $<.001$ & 0.42 & .42 & 0.04 & $<.001$ & -0.62 \\
\hline $\mathrm{PE}^{\mathrm{d}}$ to $\mathrm{BI}$ & 0.04 & .06 & 0.07 & $<.001$ & 0.14 & .16 & 0.06 & $<.001$ & -3.38 \\
\hline \multicolumn{10}{|c|}{ Age (Younger or Older) } \\
\hline EE to BI & 0.07 & .06 & 0.07 & .01 & 0.10 & .10 & 0.06 & $<.001$ & 0.34 \\
\hline SI to BI & 0.39 & .39 & 0.05 & $<.001$ & 0.42 & .40 & 0.05 & $<.001$ & 0.38 \\
\hline $\mathrm{PE}$ to $\mathrm{BI}$ & 0.13 & .12 & 0.08 & .04 & 0.04 & .05 & 0.06 & $<.001$ & 1.97 \\
\hline \multicolumn{10}{|c|}{ Group (Workers or Health experts) } \\
\hline $\mathrm{EE}$ to $\mathrm{BI}$ & 0.08 & .08 & 0.05 & .007 & 0.10 & .11 & 0.01 & .03 & 0.14 \\
\hline SI to BI & 0.38 & .40 & 0.03 & $<.001$ & 0.45 & .42 & 0.08 & $<.001$ & 0.75 \\
\hline $\mathrm{PE}$ to $\mathrm{BI}$ & 0.11 & .13 & 0.05 & $<.001$ & 0.08 & .09 & 0.01 & .03 & 0.14 \\
\hline $\mathrm{FC}^{\mathrm{e}}$ to $\mathrm{BI}$ & 0.13 & .12 & 0.05 & $<.001$ & 0.15 & .12 & 0.02 & $<.001$ & -1.65 \\
\hline $\mathrm{PR}^{\mathrm{f}}$ to $\mathrm{BI}$ & -0.18 & -.20 & 0.07 & $<.001$ & -0.36 & -.38 & 0.03 & $<.001$ & -2.24 \\
\hline
\end{tabular}

${ }^{\mathrm{a} E E}$ : effort expectancy.

${ }^{\mathrm{b}} \mathrm{BI}$ : behavioral intention.

${ }^{\mathrm{c}}$ SI: social influence.

${ }^{\mathrm{d}} \mathrm{PE}$ : performance expectancy.

${ }^{\mathrm{e}} \mathrm{FC}$ : facilitating conditions.

${ }^{\mathrm{f}} \mathrm{PR}$ : perceived risk.

\section{Differences in Perception between Workers and Health Experts}

The results of the independent samples $t$ tests to analyze differences in perception of the main variables between workers and health experts are summarized in Table 10. Workers' mean scores for the main variables were higher relative to those of health experts for all variables except perceived risk. Moreover, behavioral intention, effort expectancy, social influence, performance expectancy, and perceived risk differed significantly between groups, whereas facilitating conditions did not.

Table 10. Perception differences between groups.

\begin{tabular}{lllll}
\hline Variable & Health experts, mean (SD) & Workers, mean (SD) & t $_{864}$ & $P$ value \\
\hline $\mathrm{BI}^{\mathrm{a}}$ & $3.44(0.97)$ & $3.72(0.82)$ & -3.58 & -3.001 \\
$\mathrm{EE}^{\mathrm{b}}$ & $3.43(0.79)$ & $3.70(0.83)$ & -5.69 & $<.001$ \\
$\mathrm{SI}^{\mathrm{c}}$ & $2.92(0.92)$ & $3.34(0.86)$ & -2.20 & .03 \\
$\mathrm{PE}^{\mathrm{d}}$ & $3.90(0.58)$ & $4.01(0.60)$ & -0.69 & .49 \\
$\mathrm{FC}^{\mathrm{e}}$ & $3.59(0.73)$ & $3.63(0.84)$ & 4.85 & $<.001$ \\
$\mathrm{PR}^{\mathrm{f}}$ & $2.84(0.69)$ & $2.56(0.69)$ & & .001 \\
\hline
\end{tabular}

${ }^{\mathrm{a} B I}$ : behavioral intention.

${ }^{b}$ EE: effort expectancy.

${ }^{\mathrm{c}}$ SI: social influence.

${ }^{\mathrm{d}} \mathrm{PE}$ : performance expectancy.

${ }^{\mathrm{e}} \mathrm{FC}$ : facilitating conditions.

${ }^{f} P R$ : perceived risk. 


\section{Discussion}

The purpose of this study was to analyze the factors influencing users' behavioral intention to use a PHR app and identify differences in perception of the main variables to inform the development of personalized health care services for workers. We developed a research model that added perceived risk to the UTAUT, which is a representative theory that explains information technology acceptance, and conducted an empirical study involving health experts and workers who visited 21 workers' health centers. After receiving ethical approval from the Korea National Institute for Bioethics Policy, 1050 questionnaires were distributed over 7 weeks to 40 workers and 10 health experts from each workers' health center; 900 completed questionnaires were collected. The number of respondents in the analysis was 866 (687 workers and 179 health experts).

Performance expectancy exerted significant positive effects on behavioral intention to use the PHR app. These results are consistent with those of previous studies [24,51,56-58,62,63]. Lee et al [56] demonstrated that performance expectancy was an important determinant of app use behavioral intention between college students and workers. Liu et al [57] showed that people outside the normal range of body mass index show the closest relation to performance expectancy with a fitness app's behavioral intention. Mattila et al [18] showed that workers' requirements for personal health technologies were simplicity, integration with everyday life, and clear feedback. To increase the behavioral intention of workers on the PHR app, it is necessary to both efficiently represent the causal relationship between physiological conditions associated with the collected data, and provide functions that can help workers' health conditions through immediate feedback from health experts.

Effort expectancy exerted significant positive effects on behavioral intention to use the PHR app. These results are consistent those of previous studies [51,56,57,59,62,79]. Koivumäki et al [59] showed that effort expectancy was an important factor in consumers' behavioral intention for electronic health services using personal data. Wang et al [79] showed that effort expectancy affects the intention to use a health care app, regardless of whether or not it is used. Ensuring the ease of use of the PHR app was a top priority for developers and planners because health care services are used at various ages and in various groups; therefore, the design and use of the method must be very intuitive. No matter how much the PHR app offers, if the interface is complex, users will stop using it.

Social influence exerted significant positive effects on behavioral intention to use the PHR app. These results are also consistent with previous studies $[24,53,57,58,62,63,83,93]$. Tan et al [93] showed that social influence significantly affected the intention to use personal digital assistance devices among medical professionals. Homburg et al [104] showed that bosses' and colleagues' opinions affect the intention of subordinates to adopt new technologies. Balk-Møller et al [105] showed that social function such as a peer challenge was used for a longer time to improve workplace health promotion than other app functions. Social influence demonstrates an important role between individuals and groups in the social ecology of workers, such as colleagues, employers, and health care professionals. Employers can influence workers' behavioral intention by providing an organizational culture that facilitates using the PHR app through health management policies that promote a healthy workplace environment. Workers exerted a synergistic effect on health promotion practices if employers and health managers played an active role in workplace health promotion programs [106]. Considering that social influence exerted the strongest effect on behavioral intention to use the PHR app, the app should include functions that enable interaction between colleagues or health experts.

In addition, workers' behavioral intention increased when the app was linked to workplace health promotion activities or management direction of community institutions such as workers' health centers. Workers' health centers have conducted community institution activities such as occupational health care services for workers, on-site consultation services for the workplace, and establishing cooperative systems through networking among various institutions in the community [107]. Moreover, workers' health centers provide personalized health care services to individual workers through an understanding of workers' areas and the characteristics of industrial parks and working environments [108]. To continuously develop workers' health centers, it is necessary to build practices that systematically collect information regarding workers' medical checkups and harmful factors in the workplace and apply this information to follow-up management of the centers [107]. Under these circumstances, data collected via the PHR app can be used for personalized health care services and follow-up management of workers' health centers.

Facilitating conditions exerted significant positive effects on behavioral intention to use the PHR app. These results are consistent with previous studies $[53,58,63,83]$. Stieglitz and Brochmann [109] proposed that facilitating conditions can be divided into material support (eg, incentives) and nonmaterial support (eg, training). It is difficult to retain workers who are not interested in continuous workplace health promotion participation. If the program emphasizes external motivations such as incentives rather than cycles through which personal motivation can be generated, the degree of participation will initially increase but cannot be sustained in the long run. It is important to configure an infrastructure that can support participants. Health managers in the workplace or clinicians in the clinic can run various health care programs using the PHR app and select individuals with risk factors to help them learn about healthy lifestyles. Employers can influence workers' behavioral intention by establishing usage training, technical support teams, and organizational policies for the PHR app, along with wearable devices. Iron Mountain, a records and data management company, is running LiveWell [110], a worker health care program that uses wearable devices and apps. The program motivated workers to improve their health through policies that provide workers with various tasks and paid cash points are given to those who complete the tasks.

Perceived risk exerted a significant negative effect on behavioral intention to use the PHR app. The results showed that a greater 
possibility of loss from using the PHR app was associated with lower behavioral intention. This reflected users' concerns regarding the potential risks of using the PHR app, including potential personal information breaches. These results are consistent with previous studies [66,70,93], in which perceived risk affected the intention to use a particular technology. Choia et al [19] showed that potential risk factors such as workers' personal health information and personal location collected from wearable devices affect workers' intention to adopt the technology. Construction managers have also stressed the importance of addressing privacy issues before introducing wearable devices. Dawson et al [47] emphasized that workers are concerned about trust and confidentiality when accepting PHRs. Burkhard et al [48] noted that workers have concerns about completeness and accuracy as well as the privacy and security of PHRs. Health care technologies in the workplace enable data-based human resource management through health risk assessment for each worker. The employer may prevent disease by following a worker's condition, but the worker may be concerned about the personal disadvantages of employers obtaining and tracking personal health information. Therefore, employers need to consider the workers' perspective before introducing a PHR app in the workplace. It is important to gain the trust of workers and protect personal information through transparency of goals and procedures. Additionally, employers need to consider that (1) the purpose of the PHR app should be to facilitate a healthy culture within the workplace through workers' health promotion and disease prevention, rather than to facilitate personnel management; (2) transparency of procedures, including the purpose and utilization, should be maintained and disclosed to PHR app users; and (3) the PHR app should protect privacy with user-centered design and operation.

To protect and maintain workers' health, Korean workplaces should provide medical checkups for workers at institutions that have been designated by the Ministry of Employment and Labor or under the national health insurance law. The results of medical checkups are confidential and include not only personal information but also family history, lifestyle habits, previous history, and disease status. This information requires higher levels of protection than that required for general personal information. The results are sent directly to individual workers to strengthen personal information protection; however, this is inconvenient for health managers in the performance of their duties, because workers who lose or do not present their medical checkup results during consultations with health managers do not receive accurate consultations [111]. The PHR app can be used to collect and manage these results and share health information with specific medical personnel with consent. Moreover, it is necessary to develop security devices and specify security responsibilities for each step of medical data processing to increase the behavioral intention to use the PHR app.

The association between performance expectancy and behavioral intention of the PHR app was moderated by gender and age, where performance expectancy was higher in female and younger participants. These results are consistent with previous studies [62]. Wang et al [112] showed that women have a higher preference for health care apps than men. Guo et al [102] argued that younger individuals showed a positive attitude toward the use of new technology, whereas older individuals were often slower to acquire technology. Adas [113] reported that men were more interested in technology than women, but Fitzgerald et al [114] argued that women are more interested in health status and are therefore more likely to seek medical advice and preventive care than men. The present study showed that gender and age did not moderate the effects of effort expectancy, social influence, or behavioral intention. These results are consistent with previous studies [62,99]. Gender and age are important factors in the health care environment, but there is no strong evidence identifying their specific roles [99]. Therefore, future research should focus on moderating variables such as gender, age, educational background, and app use experience.

In addition, behavioral intention, effort expectancy, social influence, performance expectancy, and perceived risk differed between workers and health experts; workers' mean scores for the main variables were higher than those of health experts. Facilitating conditions scores did not differ between the two groups. Previous studies have identified differences in patients' and providers' perceptions, attitudes, and preferences regarding health care technologies [115], including PHRs [116]. The present study identified differences in perspective between consumers and providers regarding PHRs. PHRs are similar to EHRs in that they collect and manage individual health-related information in one place, but can be distinguished from EHRs in that individuals have ownership or control of the information. That is, providers can obtain information from PHRs only when authorized through access controls set by the consumer. According to related studies, patients with a strong need for clinical services who had chronic diseases with complications were highly likely to use PHRs [117-119], and most empirical studies have shown that patients were highly satisfied with their PHRs [119-121]. In contrast, some studies have shown that doctors were less likely to expect benefits from their patients' use of PHRs and were concerned about the impact of PHR use on their workloads $[122,123]$. However, the workload burden resulting from PHR use was found to be lower than expected, and medical personnel were generally satisfied with PHRs [120,121,124]. Since PHRs are currently in the introduction stage in Korea, most health care professionals, including health experts at workers' health centers, have no practical PHR experience. As in previous studies, concerns about increased workload, record accuracy, and the negative impact on patients from information disclosure are judged to have affected health experts' relatively low confidence in PHRs. PHR apps could help health care providers make decisions and provide information based on consumers' health records; however, they should only be implemented after conducting sufficient research examining necessary information collection and functions to ensure a balance between providers' and consumers' needs.

This study is the first to examine the factors influencing behavioral intention to use a PHR app in the field of occupational safety and health in Korea. Most studies have focused on the intention of patients, the elderly, and providers to use EHRs, health care devices, and telemedicine services; however, few have analyzed the intention to use PHR apps for workplace health promotion. This study is meaningful in that 
it reports on workers' and health experts' acceptance of interconnected PHR apps to improve workplace health promotion, but it also has some limitations. For example, the study included workers who visited workers' health centers; therefore, data were collected mainly from workplaces with fewer than 50 employees. In addition, the health experts offering health care services at workers' health centers are limited to workers in workplaces with fewer than 50 employees, and these small-scale employers are not obliged to appoint health managers. Consequently, the actual work performed by health managers may differ from that of workers' health center health experts. To derive more generalizable research results, future research should include workers and health managers from different sized workplaces. In addition, the study included only basic participant characteristics such as gender and age. Future studies should examine behavioral intention to use PHR apps according to users' health status, disease, experience, and working environments. Moreover, PHRs are currently in the introduction stage in Korea, and there has been minimal scholarly debate regarding the use of workers' PHRs. The current results could change according to the purpose and function of PHRs. Therefore, future research should examine the functions and application range of PHR apps for workers and health managers. Further, this study focused on acceptance of the PHR app for workplace health promotion through a research model that added perceived risk to the UTAUT, but it is also necessary to analyze behavioral changes in health promotion facilitated by PHR app use. Therefore, future research will analyze changes in workers' health promotion behavior associated with workplace PHR app services by applying the health belief model [125], a representative theory that explains changes in health behavior. Future study will also analyze workers' usage logs collected through the service operation as well as participants' lifestyle changes and risk factor changes associated with metabolic syndrome and service satisfaction.

\section{Acknowledgments}

This work was supported by the Creative Industrial Technology Development Program (20002708, development and commercialization of the personalized healthcare service for employees based on the PHR platform), which is funded by the Ministry of Trade, Industry and Energy in Korea. We would like to thank the Korea Occupational Safety and Health Agency and the 21 workers' health centers nationwide for their help in data collection.

\section{Conflicts of Interest}

None declared.

\section{Multimedia Appendix 1}

Overview of the instrument.

[DOCX File, 29 KB-Multimedia Appendix 1]

\section{References}

1. United States Department of Health and Human Services. Healthy People 2010: Understanding and improving health Volumes 1-2. Burlington, MA: Jones and Bartlett Publishers; 2001.

2. Melzner J, Heinze J, Fritsch T. Mobile Health Applications in Workplace Health Promotion: An Integrated Conceptual Adoption Framework. Proced Technol 2014;16:1374-1382. [doi: 10.1016/j.protcy.2014.10.155]

3. Burton J. WHO healthy workplace framework and model: background and supporting literature and practices. Geneva, Switzerland: World Health Organization; 2010. URL: https://www.who.int/occupational health/ healthy_workplace framework.pdf [accessed 2020-04-30]

4. Federal Institute for Occupational Safety and Health. Luxembourg Declaration on Workplace health promotion in the European Union.: Bundesanstalt für Arbeitschutz und Arbeitsmedizin; 1997. URL: https://www.enwhp.org/resources/toolip/ doc/2018/05/04/luxembourg_declaration.pdf [accessed 2020-04-30]

5. Pohjonen T, Ranta R. Effects of worksite physical exercise intervention on physical fitness, perceived health status, and work ability among home care workers: five-year follow-up. Prev Med 2001 Jun;32(6):465-475. [doi: 10.1006/pmed.2001.0837] [Medline: 11394950]

6. Robroek SJ, van LFJ, van EP, Burdorf A. Determinants of participation in worksite health promotion programmes: a systematic review. Int J Behav Nutr Phys Act 2009;6:26 [FREE Full text] [doi: 10.1186/1479-5868-6-26] [Medline: 19457246]

7. Bull SS, Gillette C, Glasgow RE, Estabrooks P. Work site health promotion research: to what extent can we generalize the results and what is needed to translate research to practice? Health Educ Behav 2003 Oct 30;30(5):537-549. [doi: 10.1177/1090198103254340] [Medline: 14582596]

8. Griffiths F, Lindenmeyer A, Powell J, Lowe P, Thorogood M. Why are health care interventions delivered over the internet? A systematic review of the published literature. J Med Internet Res 2006 Jun;8(2):e10 [FREE Full text] [doi: 10.2196/jmir.8.2.e10] [Medline: 16867965] 
9. Cook RF, Billings DW, Hersch RK, Back AS, Hendrickson A. A field test of a web-based workplace health promotion program to improve dietary practices, reduce stress, and increase physical activity: randomized controlled trial. J Med Internet Res 2007 Jun 19;9(2):e17 [FREE Full text] [doi: 10.2196/jmir.9.2.e17] [Medline: 17581811]

10. Hasson H, Brown C, Hasson D. Factors associated with high use of a workplace web-based stress management program in a randomized controlled intervention study. Health Educ Res 2010 Aug;25(4):596-607. [doi: 10.1093/her/cyq005] [Medline: 20150531]

11. Kim NJ. Relation between employees' life patterns and health conditions. Korean J Health Edu Promot 2007;24(2):63-75 [FREE Full text]

12. Pronk NP, Katz AS, Lowry M, Payfer JR. Reducing occupational sitting time and improving worker health: the Take-a-Stand Project, 2011. Prev Chronic Dis 2012 Oct 11;9:E154 [FREE Full text] [doi: 10.5888/pcd9.110323] [Medline: 23057991]

13. KOSTAT. 2017. Cause of Death Statistics in 2017 - Statistics Korea URL: http://kostat.go.kr/portal/eng/pressReleases/8/

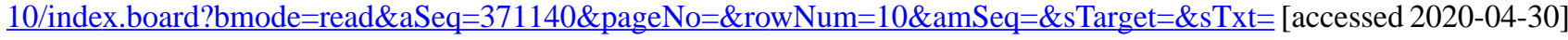

14. Korea National Health Insurance Service. In: National Health Insurance Statistical Yearbook. Wonju-si, Gangwon-do, Korea: NHIS Press; 2016.

15. Chronic Diseases Factbook. Cheongju-si, Chungcheongbuk-do, Korea: KCDC Press; 2018.

16. Schultz AB, Edington DW. Metabolic syndrome in a workplace: prevalence, co-morbidities, and economic impact. Metab Syndr Relat Disord 2009 Oct;7(5):459-468. [doi: 10.1089/met.2009.0008] [Medline: 19450154]

17. Sook CE, Ja JK. The management strategies of metabolic syndrome among workers through the literature review. Korean J Occup Health Nurs 2005;14(2):138-152 [FREE Full text]

18. Silberman J, Schwartz S, Giuseffi DL, Wang C, Nevedal D, Bedrosian R. Reductions in Employee Productivity Impairment Observed After Implementation of Web-Based Worksite Health Promotion Programs. J Occup Environ Med 2011;53(12):1404-1412. [doi: 10.1097/jom.0b013e3182337726]

19. Petersen R, Sill S, Lu C, Young J, Edington DW. Effectiveness of employee internet-based weight management program. J Occup Environ Med 2008 Feb;50(2):163-171. [doi: 10.1097/JOM.0b013e31815c6cf6] [Medline: 18301173]

20. Mattila E, Orsama A, Ahtinen A, Hopsu L, Leino T, Korhonen I. Personal health technologies in employee health promotion: usage activity, usefulness, and health-related outcomes in a 1-year randomized controlled trial. JMIR Mhealth Uhealth 2013 Jul 29;1(2):e16 [FREE Full text] [doi: 10.2196/mhealth.2557] [Medline: 25098385]

21. Balk-Møller NC, Larsen TM, Holm L. Experiences From a Web- and App-Based Workplace Health Promotion Intervention Among Employees in the Social and Health Care Sector Based on Use-Data and Qualitative Interviews. J Med Internet Res 2017 Oct 19;19(10):e350 [FREE Full text] [doi: 10.2196/jmir.7278] [Medline: 29051133]

22. Choi B, Hwang S, Lee S. What drives construction workers' acceptance of wearable technologies in the workplace?: Indoor localization and wearable health devices for occupational safety and health. Automat Construct 2017 Dec;84:31-41. [doi: 10.1016/j.autcon.2017.08.005]

23. Davis FD. Perceived Usefulness, Perceived Ease of Use, and User Acceptance of Information Technology. MIS Quart 1989 Sep;13(3):319-340. [doi: 10.2307/249008]

24. Mohadis H, Ali N. Smartphone application for physical activity enhancement at workplace: would office workers actually use it? : IEEE; 2018 Presented at: 2018 International Conference on Information and Communication Technology for the Muslim World; July 23-25, 2018; Kuala Lumpur, Malaysia p. 144-149. [doi: 10.1109/ict4m.2018.00035]

25. Venkatesh M, Morris MG, Davis GB, Davis FB. User Acceptance of Information Technology: Toward a Unified View. MIS Quart 2003;27(3):425. [doi: 10.2307/30036540]

26. Sari H, Othman M, Al-Ghaili A. A Proposed conceptual framework for mobile health technology adoption among employees at workplaces in Malaysia. : IRICT; 2018 Presented at: Proceedings of the 3rd International Conference of Reliable Information and Communication Technology; June 23-24, 2018; Kuala Lumpur, Malaysia. [doi: 10.1007/978-3-319-99007-1 68]

27. Siddiqui M, Islam MYU, Mufti BAI, Khan N, Farooq MS, Muhammad MG, et al. Assessing acceptability of hypertensive/diabetic patients towards mobile health based behavioral interventions in Pakistan: A pilot study. Int J Med Inform 2015 Nov;84(11):950-955. [doi: 10.1016/j.ijmedinf.2015.08.009] [Medline: 26321485]

28. Lim S, Xue L, Yen CC, Chang L, Chan HC, Tai BC, et al. A study on Singaporean women's acceptance of using mobile phones to seek health information. Int J Med Inform 2011 Dec;80(12):e189-e202. [doi: 10.1016/j.ijmedinf.2011.08.007] [Medline: 21956003]

29. Koehler N, Vujovic O, McMenamin C. Healthcare professionals' use of mobile phones and the internet in clinical practice. JournalMTM 2013;2(1):3-13. [doi: 10.7309/jmtm.2.1.2]

30. To QG, Chen TTL, Magnussen CG, To KG. Workplace physical activity interventions: a systematic review. Am J Health Promot 2013 Jul;27(6):e113-e123. [doi: 10.4278/ajhp.120425-LIT-222] [Medline: 23631453]

31. Dunkl A, Jiménez P. Using smartphone-based applications (apps) in workplace health promotion: The opinion of German and Austrian leaders. Health Informatics J 2017 Mar;23(1):44-55. [doi: 10.1177/1460458215623077] [Medline: 26833401]

32. Khaneghah P, Miguel-Cruz A, Bentley P, Liu L, Stroulia E, Ferguson-Pell M. Users' Attitudes Towards Personal Health Records: A Cross-Sectional Pilot Study. Appl Clin Inform 2016 Dec 16;7(2):573-586 [FREE Full text] [doi: 10.4338/ACI-2015-12-RA-0180] [Medline: 27437062] 
33. Kim J, Jung H, Bates DW. History and Trends of "Personal Health Record" Research in PubMed. Healthc Inform Res 2011 Mar;17(1):3-17 [FREE Full text] [doi: 10.4258/hir.2011.17.1.3] [Medline: 21818452]

34. Lyons EJ, Lewis ZH, Mayrsohn BG, Rowland JL. Behavior change techniques implemented in electronic lifestyle activity monitors: a systematic content analysis. J Med Internet Res 2014 Aug;16(8):e192 [FREE Full text] [doi: 10.2196/jmir.3469] [Medline: 25131661]

35. Michie S, Abraham C, Whittington C, McAteer J, Gupta S. Effective techniques in healthy eating and physical activity interventions: a meta-regression. Health Psychol 2009 Nov;28(6):690-701. [doi: 10.1037/a0016136] [Medline: 19916637]

36. Michie S, Ashford S, Sniehotta FF, Dombrowski SU, Bishop A, French DP. A refined taxonomy of behaviour change techniques to help people change their physical activity and healthy eating behaviours: the CALO-RE taxonomy. Psychol Health 2011 Nov;26(11):1479-1498. [doi: 10.1080/08870446.2010.540664] [Medline: 21678185]

37. Park HS, Cho H, Kim HS. Development of a Multi-Agent m-Health Application Based on Various Protocols for Chronic Disease Self-Management. J Med Syst 2016 Jan 14;40(1):36. [doi: 10.1007/s10916-015-0401-5] [Medline: 26573657]

38. Institute of Medicine of the National Academies. Incorporating Occupational Information In Electronic Health Records: Letter Report. Washington, DC: National Academies Press; 2011.

39. Rajamani S, Chen ES, Lindemann E, Aldekhyyel R, Wang Y, Melton GB. Representation of occupational information across resources and validation of the occupational data for health model. J Am Med Inform Assoc 2018 Feb 01;25(2):197-205 [FREE Full text] [doi: 10.1093/jamia/ocx035] [Medline: 28444213]

40. HL7 FHIR Profile: Occupational Data for Health (ODH), Release 1. HL7 International URL: http://hl7.org/fhir/us/odh/ 2018Sep/ [accessed 2019-10-08]

41. Connecting Americans to their health care. 2004. Connecting for Health: Markle Foundation URL: https://www.markle.org/ sites/default/files/CnctAmerHC fullreport.pdf [accessed 2019-10-08]

42. Ant OA, Wu H, Garrido M, Pronovost PJ, Gurses AP. Usability and perceived usefulness of Personal Health Records for preventive health care: a case study focusing on patients' and primary care providers' perspectives. Appl Ergon 2014 May;45(3):613-628. [doi: 10.1016/j.apergo.2013.09.005] [Medline: 24119975]

43. Huba N, Zhang Y. Designing patient-centered personal health records (PHRs): health care professionals' perspective on patient-generated data. J Med Syst 2012 Dec 30;36(6):3893-3905. [doi: 10.1007/s10916-012-9861-z] [Medline: 22644130]

44. Reti SR, Feldman HJ, Safran C. Governance for Personal Health Records. J Am Med Inform Assoc 2009 Jan 01;16(1):14-17. [doi: 10.1197/jamia.m2854]

45. Kaelber D, Pan EC. The value of personal health record (PHR) systems. AMIA Annu Symp Proc 2008 Nov 06:343-347 [FREE Full text] [Medline: 18999276]

46. Agarwal R, Anderson C, Zarate J, Ward C. If we offer it, will they accept? Factors affecting patient use intentions of personal health records and secure messaging. J Med Internet Res 2013 Feb;15(2):e43 [FREE Full text] [doi: 10.2196/jmir.2243] [Medline: 23470453]

47. Dawson J, Schooley B, Tulu B. A real world perspective: employee perspectives of employer sponsored personal health record (PHR) systems. : IEEE; 2009 Presented at: Proceedings of 42nd Hawaii International Conference on System Sciences 2009; January 5-8, 2009; Big Island, HI, USA. [doi: 10.1109/HICSS.2009.34]

48. Burkhard RJ, Schooley B, Dawson J, Horan TA. Information Systems and Healthcare XXXVII: When Your Employer Provides Your Personal Health Record-Exploring Employee Perceptions of an Employer-Sponsored PHR System. Commun Asssoc Inform Syst 2010;27:19. [doi: 10.17705/1cais.02719]

49. Pirtle B, Chandra A. An Overview Of Consumer Perceptions And Acceptance As Well As Barriers And Potential Of Electronic Personal Health Records. Am J Health Sci 2011 Nov 22;2(2):45-52. [doi: 10.19030/ajhs.v2i2.6627]

50. Spil T, Klein R. Personal health records success: why Google Health failed and what does that mean for Microsoft HealthVault? : IEEE; 2014 Presented at: Proceedings of 47th Hawaii International Conference on System Sciences 2014; 2014; Waikoloa, HI, USA p. 6-9. [doi: 10.1109/hicss.2014.353]

51. Hsieh H, Kuo Y, Wang S, Chuang B, Tsai C. A Study of Personal Health Record User's Behavioral Model Based on the PMT and UTAUT Integrative Perspective. Int J Environ Res Public Health 2016 Dec 23;14(1):8 [FREE Full text] [doi: 10.3390/ijerph14010008] [Medline: 28025557]

52. Bauer RA. Consumer behavior as risk taking. Cambridge: Harvard University Press; 1960:13-21.

53. Kim S, Lee K, Hwang H, Yoo S. Analysis of the factors influencing healthcare professionals' adoption of mobile electronic medical record (EMR) using the unified theory of acceptance and use of technology (UTAUT) in a tertiary hospital. BMC Med Inform Decis Mak 2016 Jan 30;16(1):12 [FREE Full text] [doi: 10.1186/s12911-016-0249-8] [Medline: 26831123]

54. Lee S, Yoo W, Park H, Kim S. An Empirical Study on Acceptance Intention Towards Healthcare Wearable Device. J Inform Syst 2016 Jun 30;25(2):27-50. [doi: 10.5859/kais.2016.25.2.27]

55. Gao Y, Li H, Luo Y. An empirical study of wearable technology acceptance in healthcare. Industr Manage Data Syst 2015 Oct 19;115(9):1704-1723. [doi: 10.1108/IMDS-03-2015-0087]

56. Lee HS, Kim TG, Choi JY. A study on the factors affecting smart phone application acceptance. : IACSIT; 2012 Presented at: Proceedings of 2012 3rd International Conference on e-Education, e-Business, e-Management and E-Learning 2012; January 5-7, 2012; Hong Kong. 
57. Liu D, Maimaitijiang R, Gu J, Zhong S, Zhou M, Wu Z, et al. Using the Unified Theory of Acceptance and Use of Technology (UTAUT) to Investigate the Intention to Use Physical Activity Apps: Cross-Sectional Survey. JMIR Mhealth Uhealth 2019 Aug 22;7(9):e13127 [FREE Full text] [doi: 10.2196/13127] [Medline: 31507269]

58. Zhang Y, Liu C, Luo S, Xie Y, Liu F, Li X, et al. Factors Influencing Patients' Intentions to Use Diabetes Management Apps Based on an Extended Unified Theory of Acceptance and Use of Technology Model: Web-Based Survey. J Med Internet Res 2019 Aug 13;21(8):e15023 [FREE Full text] [doi: 10.2196/15023] [Medline: 31411146]

59. Koivumäki T, Pekkarinen S, Lappi M, Väisänen J, Juntunen J, Pikkarainen M. Consumer Adoption of Future MyData-Based Preventive eHealth Services: An Acceptance Model and Survey Study. J Med Internet Res 2017 Dec 22;19(12):e429 [FREE Full text] [doi: 10.2196/jmir.7821] [Medline: 29273574]

60. Cranen K, Drossaert CHC, Brinkman ES, Braakman-Jansen ALM, Ijzerman MJ, Vollenbroek-Hutten MMR. An exploration of chronic pain patients' perceptions of home telerehabilitation services. Health Expect 2012 Dec;15(4):339-350. [doi: 10.1111/j.1369-7625.2011.00668.x] [Medline: 21348905]

61. Lee J, Rho MJ. Perception of Influencing Factors on Acceptance of Mobile Health Monitoring Service: A Comparison between Users and Non-users. Healthc Inform Res 2013 Sep;19(3):167-176 [FREE Full text] [doi: 10.4258/hir.2013.19.3.167] [Medline: 24175115]

62. Rho MJ, Kim HS, Chung K, Choi IY. Factors influencing the acceptance of telemedicine for diabetes management. Cluster Comput 2014 Mar 12;18(1):321-331. [doi: 10.1007/s10586-014-0356-1]

63. Hsu C, Tseng KC, Chuang Y. Predictors of Future Use of Telehomecare Health Services by Middle-Aged People in Taiwan. Soc Behav Personal 2011 Oct 14;39(9):1251-1261. [doi: 10.2224/sbp.2011.39.9.1251]

64. Short JF. The Social Fabric at Risk: Toward the Social Transformation of Risk Analysis. Am Sociol Rev 1984 Dec;49(6):711. [doi: $10.2307 / 2095526]$

65. Rayner S, Cantor R. How Fair Is Safe Enough? The Cultural Approach to Societal Technology Choice1. Risk Analysis 1987 Mar;7(1):3-9. [doi: 10.1111/j.1539-6924.1987.tb00963.x]

66. Lu Y, Yang S, Chau PY, Cao Y. Dynamics between the trust transfer process and intention to use mobile payment services: A cross-environment perspective. Inform Manage 2011 Dec;48(8):393-403. [doi: 10.1016/j.im.2011.09.006]

67. Chiu CM, Wang ETG, Fang YH, Huang HY. Understanding customers' repeat purchase intentions in B2C e commerce: the roles of utilitarian value, hedonic value and perceived risk. Inform Syst J 2014;24(1):85-114. [doi: 10.1111/j.1365-2575.2012.00407.x]

68. Ayanso A, Herath TC, O'Brien N. Understanding continuance intentions of physicians with electronic medical records (EMR): An expectancy-confirmation perspective. Decision Support Syst 2015 Sep;77:112-122. [doi: 10.1016/j.dss.2015.06.003]

69. Schnall R, Higgins T, Brown W, Carballo-Dieguez A, Bakken S. Trust, Perceived Risk, Perceived Ease of Use and Perceived Usefulness as Factors Related to mHealth Technology Use. Stud Health Technol Inform 2015;216:467-471 [FREE Full text] [Medline: 26262094]

70. Deng Z, Hong Z, Ren C, Zhang W, Xiang F. What Predicts Patients' Adoption Intention Toward mHealth Services in China: Empirical Study. JMIR Mhealth Uhealth 2018 Aug 29;6(8):e172 [FREE Full text] [doi: 10.2196/mhealth.9316] [Medline: 30158101]

71. Analysis of industrial accident situation. Sejong, Korea: MOEL Press; 2017.

72. Industrial health: health care for disadvantaged workers. Seoul, Korea: KIHA Press; 1994.

73. Industrial health: today and tomorrow of small scale industries in the western Pacific region health services. Seoul, Korea: KIHA Press; 1994.

74. Ware LJ, Hurling R, Bataveljic O, Fairley BW, Hurst TL, Murray P, et al. Rates and determinants of uptake and use of an internet physical activity and weight management program in office and manufacturing work sites in England: cohort study. J Med Internet Res 2008 Dec;10(4):e56 [FREE Full text] [doi: 10.2196/jmir.1108] [Medline: 19117828]

75. Spittaels H, De BI, Brug J, Vandelanotte C. Effectiveness of an online computer-tailored physical activity intervention in a real-life setting. Health Educ Res 2007 Jun;22(3):385-396. [doi: 10.1093/her/cyl096] [Medline: 16971674]

76. van DWS, Verwey R, Spreeuwenberg M, Tange H, van DWT, de WL. The development of a mobile monitoring and feedback tool to stimulate physical activity of people with a chronic disease in primary care: a user-centered design. JMIR Mhealth Uhealth 2013 Jul;1(2):e8 [FREE Full text] [doi: 10.2196/mhealth.2526] [Medline: 25099556]

77. Soler RE, Leeks KD, Razi S, Hopkins DP, Griffith M, Aten A, Task Force on Community Preventive Services. A systematic review of selected interventions for worksite health promotion. The assessment of health risks with feedback. Am J Prev Med 2010 Feb;38(Suppl 2):S237-S262. [doi: 10.1016/j.amepre.2009.10.030] [Medline: 20117610]

78. Chang I, Hwang H, Hung W, Li Y. Physicians' acceptance of pharmacokinetics-based clinical decision support systems. Expert Syst Appl 2007 Aug;33(2):296-303. [doi: 10.1016/j.eswa.2006.05.001]

79. Wang BR, Park J, Chung K, Choi IY. Influential Factors of Smart Health Users according to Usage Experience and Intention to Use. Wireless Pers Commun 2014 Apr 24;79(4):2671-2683. [doi: 10.1007/s11277-014-1769-0]

80. Chau PY, Hu PJ. Examining a Model of Information Technology Acceptance by Individual Professionals: An Exploratory Study. J Manage Inform Syst 2014 Dec 23;18(4):191-229. [doi: 10.1080/07421222.2002.11045699] 
81. Moore GC, Benbasat I. Development of an Instrument to Measure the Perceptions of Adopting an Information Technology Innovation. Inform Syst Res 1991 Sep;2(3):192-222. [doi: 10.1287/isre.2.3.192]

82. Dennison L, Morrison L, Conway G, Yardley L. Opportunities and challenges for smartphone applications in supporting health behavior change: qualitative study. J Med Internet Res 2013 Apr;15(4):e86 [FREE Full text] [doi: 10.2196/jmir.2583] [Medline: 23598614]

83. Aggelidis VP, Chatzoglou PD. Using a modified technology acceptance model in hospitals. Int J Med Inform 2009 Feb;78(2):115-126. [doi: 10.1016/j.ijmedinf.2008.06.006] [Medline: 18675583]

84. Wu J, Wang S, Lin L. Mobile computing acceptance factors in the healthcare industry: a structural equation model. Int J Med Inform 2007 Jan;76(1):66-77. [doi: 10.1016/j.ijmedinf.2006.06.006] [Medline: 16901749]

85. Schein E. Organizational Culture And Leadership (J-B US Non-Franchise Leadership). San Francisco, CA: Jossey-Bass; 2004.

86. Chung S, Lee KY, Kim K. Job performance through mobile enterprise systems: The role of organizational agility, location independence, and task characteristics. Inform Manage 2014 Sep;51(6):605-617. [doi: 10.1016/j.im.2014.05.007]

87. Hartnell CA, Ou AY, Kinicki A. Organizational culture and organizational effectiveness: A meta-analytic investigation of the competing values framework's theoretical suppositions": Correction to Hartnell, Ou, and Kinicki (2011). J Appl Psychol 2011;96(4):694-694. [doi: 10.1037/a0023086]

88. Rahman AA, Kamarulzaman NH, Sambasivan M. A study on organizational culture, performance, and technological adoption behaviours of Malaysian food processing SMEs. Pertanika J Soc Sci Hum 213;21:231-256.

89. Tsai Y. Relationship between organizational culture, leadership behavior and job satisfaction. BMC Health Serv Res 2011 May 14;11(1):98 [FREE Full text] [doi: 10.1186/1472-6963-11-98] [Medline: 21569537]

90. Mitropoulos P, Memarian B. Team Processes and Safety of Workers: Cognitive, Affective, and Behavioral Processes of Construction Crews. J Constr Eng Manage 2012 Oct;138(10):1181-1191. [doi: 10.1061/(asce)co.1943-7862.0000527]

91. Son H, Park Y, Kim C, Chou J. Toward an understanding of construction professionals' acceptance of mobile computing devices in South Korea: An extension of the technology acceptance model. Automat Construct 2012 Dec;28:82-90. [doi: 10.1016/j.autcon.2012.07.002]

92. Wang T, Jung C, Kang M, Chung Y. Exploring determinants of adoption intentions towards Enterprise 2.0 applications: an empirical study. Behav Inform Technol 2013 Apr 16;33(10):1048-1064. [doi: 10.1080/0144929x.2013.781221]

93. Tan GWH, Siah MW, Ooi KB, Hew TS, Chong AYL. The adoption of PDA for future healthcare system: an emerging market perspective. IJMC 2015;13(1):1. [doi: 10.1504/ijmc.2015.065887]

94. Saleem Z, Rashid K. Mobile banking adoption in banking sector of Pakistan. J Yasar Univ 2011;6(21):3538-3560.

95. Roberts FD, Kelley CL, Medlin BD. Factors influencing accounting faculty member' decision to adopt technology in the classroom. College Student J 2007;41(2):423-435.

96. Yueh HP, Liu YL, Chen TL, Chen GD. Exploring key factors of corporate e-learning implementation using cases of enterprises participated in National Corporate e-Learning Projects. J Bus Admin 2010;85:1-20.

97. Jimenez P, Bregenzer A. Integration of eHealth Tools in the Process of Workplace Health Promotion: Proposal for Design and Implementation. J Med Internet Res 2018 Feb 23;20(2):e65 [FREE Full text] [doi: 10.2196/jmir.8769] [Medline: 29475828]

98. Abdelhamid M, Gaia J, Sanders GL. Putting the Focus Back on the Patient: How Privacy Concerns Affect Personal Health Information Sharing Intentions. J Med Internet Res 2017 Sep 13;19(9):e169 [FREE Full text] [doi: 10.2196/jmir.6877] [Medline: 28903895]

99. Aldosari B. User acceptance of a picture archiving and communication system (PACS) in a Saudi Arabian hospital radiology department. BMC Med Inform Decis Mak 2012 May 28;12(1):44 [FREE Full text] [doi: 10.1186/1472-6947-12-44] [Medline: 22640490]

100. Duyck P, Pynoo B, Devolder P, Voet T, Adang L, Ovaere D, et al. Monitoring the PACS implementation process in a large university hospital--discrepancies between radiologists and physicians. J Digit Imaging 2010 Feb 28;23(1):73-80 [FREE Full text] [doi: 10.1007/s10278-008-9163-7] [Medline: 18956231]

101. Holden RJ, Karsh B. The technology acceptance model: its past and its future in health care. J Biomed Inform 2010 Feb;43(1):159-172 [FREE Full text] [doi: 10.1016/j.jbi.2009.07.002] [Medline: 19615467]

102. Guo X, Han X, Zhang X, Dang Y, Chen C. Investigating m-Health Acceptance from a Protection Motivation Theory Perspective: Gender and Age Differences. Telemed J E Health 2015 Aug;21(8):661-669. [doi: 10.1089/tmj.2014.0166] [Medline: 25919800]

103. Ratner B. The correlation coefficient: Its values range between $+1 /-1$, or do they? J Target Meas Anal Mark 2009 May 18;17(2):139-142. [doi: $10.1057 /$ it.2009.5]

104. Homburg C, Wieseke J, Kuehnl C. Social influence on salespeople's adoption of sales technology: a multilevel analysis. J Acad Market Sci 2009 Jul 21;38(2):159-168. [doi: 10.1007/s11747-009-0157-x]

105. Balk-Møller NC, Larsen TM, Holm L. Experiences From a Web- and App-Based Workplace Health Promotion Intervention Among Employees in the Social and Health Care Sector Based on Use-Data and Qualitative Interviews. J Med Internet Res 2017 Oct 19;19(10):e350 [FREE Full text] [doi: 10.2196/jmir.7278] [Medline: 29051133] 
106. Fisher EB, Bishop DB, Mayer J, Brown T, White-Cook T. The physicians's contribution to smoking cessation in the workplace. Chest 1988 Feb;93(Suppl 2):56S-65S. [doi: 10.1378/chest.93.2 supplement.56s] [Medline: $\underline{3276462]}$

107. Kim J, Kim D, Gil H, Park Y, Sin H, Park J. Significance and prospect of workers health center. J Korean Med Assoc 2014;57(2):159. [doi: 10.5124/jkma.2014.57.2.159]

108. Nam K, Park J, Koh J, Kim J, Park J, Kim H, et al. An Assessment of the Needs and the Affecting Factors for Small Scale Enterprise Worker's Health Centers. Korean J Occup Environ Med 2011;23(4):407. [doi: 10.35371/kjoem.2011.23.4.407]

109. Holden RJ, Karsh B. The technology acceptance model: its past and its future in health care. J Biomed Inform 2010 Feb;43(1):159-172 [FREE Full text] [doi: 10.1016/j.jbi.2009.07.002] [Medline: 19615467]

110. IRON MOUNTAIN: Live Well. URL: https://ironmountain.mywellmetrics.com/ [accessed 2020-02-25]

111. Jeong S, Kim M, Lee C, Lee C, Son B, Kim D, et al. Cognition and Practice on Medical Information Protection of Iudustrial Health Care Manager of Small and Medium Sized Enterprises. Korean J Occup Environ Med 2011;23(1):53. [doi: 10.35371/kjoem.2011.23.1.53]

112. Wang B, Park J, Choi I. Influencing Factors for the Adoption of Smartphone Healthcare Application. J Korea Contents Assoc 2011 Oct 28;11(10):396-404. [doi: 10.5392/jkca.2011.11.10.396]

113. Brower R. Machines as the measure of men: Science, technology and the ideologies of western dominance [Review]. IEEE Technol Soc Mag 1993;12(3):4. [doi: 10.1109/mtas.1993.232278]

114. Fitzgerald JT, Anderson RM, Davis WK. Gender differences in diabetes attitudes and adherence. Diabetes Educ 1995 Jun 30;21(6):523-529. [doi: 10.1177/014572179502100605] [Medline: $\underline{\text { 8549255] }}$

115. Angst CM, Agarwal R. Adoption of Electronic Health Records in the Presence of Privacy Concerns: The Elaboration Likelihood Model and Individual Persuasion. MIS Quart 2009;33(2):339-370. [doi: 10.2307/20650295]

116. Baird A, North F, Raghu T. Personal health records (PHR) and the future of the physician-patient relationship. USA: ACM; 2011 Presented at: Proceedings of the 6th Annual Conference on 2011 iConference; February 8-11, 2011; Seattle, WA. [doi: 10.1145/1940761.1940800]

117. Hsu J, Huang J, Kinsman J, Fireman B, Miller R, Selby J, et al. Use of e-Health services between 1999 and 2002 : a growing digital divide. J Am Med Inform Assoc 2005;12(2):164-171 [FREE Full text] [doi: 10.1197/jamia.M1672] [Medline: 15561786]

118. Miller H, Vandenbosch B, Ivanov D, Black P. Determinants of personal health record use: a large population study at Cleveland Clinic. J Healthc Inf Manag 2007;21(3):44-48. [Medline: 19195293]

119. Ralston JD, Carrell D, Reid R, Anderson M, Moran M, Hereford J. Patient web services integrated with a shared medical record: patient use and satisfaction. J Am Med Inform Assoc 2007 Nov;14(6):798-806. [doi: 10.1197/jamia.M2302] [Medline: 17712090$]$

120. Hassol A, Walker JM, Kidder D, Rokita K, Young D, Pierdon S, et al. Patient experiences and attitudes about access to a patient electronic health care record and linked web messaging. J Am Med Inform Assoc 2004 Nov;11(6):505-513 [FREE Full text] [doi: 10.1197/jamia.M1593] [Medline: 15299001]

121. Tang PC, Lansky D. The missing link: bridging the patient-provider health information gap. Health Aff (Millwood) 2005 Sep;24(5):1290-1295. [doi: 10.1377/hlthaff.24.5.1290] [Medline: 16162575]

122. Kittler A, Carlson GL, Harris C, Lippincott M, Pizziferri L, Volk LA, et al. Primary care physician attitudes towards using a secure web-based portal designed to facilitate electronic communication with patients. Inform Prim Care 2004 Nov 01;12(3):129-138 [FREE Full text] [doi: 10.14236/jhi.v12i3.118] [Medline: 15606985]

123. Ross SE, Todd J, Moore LA, Beaty BL, Wittevrongel L, Lin C. Expectations of patients and physicians regarding patient-accessible medical records. J Med Internet Res 2005 May 24;7(2):e13 [FREE Full text] [doi: 10.2196/jmir.7.2.e13] [Medline: $\underline{15914460}$ ]

124. White CB. A Content Analysis of E-mail Communication between Patients and Their Providers: Patients Get the Message. J Am Med Inform Assoc 2004 Apr 02;11(4):260-267. [doi: 10.1197/jamia.m1445]

125. Janz NK, Becker MH. The Health Belief Model: a decade later. Health Educ Q 1984 Jan 01;11(1):1-47. [doi: 10.1177/109019818401100101] [Medline: 6392204]

\section{Abbreviations}

EHR: electronic health record

FHIR: fast healthcare interoperability resource

HL7: Health Level Seven

mHealth: mobile health

PHR: personal health record

TAM: technology acceptance model

UTAUT: unified theory of acceptance and use of technology 
Edited by G Eysenbach; submitted 17.10.19; peer-reviewed by P Jimenez, Y Huang, T Higgins; comments to author 03.02.20; revised version received 16.03.20; accepted 30.03.20; published 04.06.20

Please cite as:

Park HS, Kim KI, Soh JY, Hyun YH, Jang SK, Lee S, Hwang GY, Kim HS

Factors Influencing Acceptance of Personal Health Record Apps for Workplace Health Promotion: Cross-Sectional Questionnaire Study

JMIR Mhealth Uhealth 2020;8(6):e16723

URL: https://mhealth.jmir.org/2020/6/e16723

doi: $\underline{10.2196 / 16723}$

PMID: $\underline{32496202}$

CHyun Sang Park, Kwang Il Kim, Jae Young Soh, Young Ho Hyun, Sae Kyun Jang, Sol Lee, Ga Young Hwang, Hwa Sun Kim. Originally published in JMIR mHealth and uHealth (http://mhealth.jmir.org), 04.06.2020. This is an open-access article distributed under the terms of the Creative Commons Attribution License (https://creativecommons.org/licenses/by/4.0/), which permits unrestricted use, distribution, and reproduction in any medium, provided the original work, first published in JMIR mHealth and uHealth, is properly cited. The complete bibliographic information, a link to the original publication on http://mhealth.jmir.org/, as well as this copyright and license information must be included. 